\title{
Peroxidized Linoleic Acid, 13-HPODE, Alters Gene Expression Profile in Intestinal Epithelial Cells
}

\author{
Nisreen Faizo ${ }^{1}{ }^{\circ}$, Chandrakala Aluganti Narasimhulu ${ }^{2}$, Anna Forsman ${ }^{3}{ }^{\circledR}$, Shibu Yooseph $^{4, *}$ \\ and Sampath Parthasarathy ${ }^{2}$ \\ 1 Burnett School of Biomedical Sciences, Genomics and Bioinformatics Cluster, College of Medicine, \\ University of Central Florida, Orlando, FL 32816, USA; nfaizo@knights.ucf.edu \\ 2 Burnett School of Biomedical Sciences, College of Medicine, University of Central Florida, \\ Orlando, FL 32816, USA; Chandrakala.AlugantiNarasimhulu@ucf.edu (C.A.N.); spartha@ucf.edu (S.P.) \\ 3 Department of Biology, Genomics and Bioinformatics Cluster, University of Central Florida, \\ Orlando, FL 32816, USA; Anna.Forsman@ucf.edu \\ 4 Department of Computer Science, Genomics and Bioinformatics Cluster, University of Central Florida, \\ Orlando, FL 32816, USA \\ * Correspondence: Shibu.Yooseph@ucf.edu; Tel.: +1-407-823-5307
}

Citation: Faizo, N.; Narasimhulu, C.A.; Forsman, A.; Yooseph, S.; Parthasarathy, S. Peroxidized Linoleic Acid, 13-HPODE, Alters Gene

Expression Profile in Intestinal Epithelial Cells. Foods 2021, 10, 314. https://doi.org/10.3390/ foods10020314

Received: 29 December 2020

Accepted: 31 January 2021

Published: 3 February 2021

Publisher's Note: MDPI stays neutral with regard to jurisdictional claims in published maps and institutional affiliations.

Copyright: (c) 2021 by the authors. Licensee MDPI, Basel, Switzerland. This article is an open access article distributed under the terms and conditions of the Creative Commons Attribution (CC BY) license (https:/ / creativecommons.org/licenses/by/ $4.0 /)$.

\begin{abstract}
Lipid peroxides (LOOHs) abound in processed food and have been implicated in the pathology of diverse diseases including gut, cardiovascular, and cancer diseases. Recently, RNA Sequencing (RNA-seq) has been widely used to profile gene expression. To characterize gene expression and pathway dysregulation upon exposure to peroxidized linoleic acid, we incubated intestinal epithelial cells (Caco-2) with $100 \mu \mathrm{M}$ of 13-hydroperoxyoctadecadienoic acid (13-HPODE) or linoleic acid (LA) for $24 \mathrm{~h}$. Total RNA was extracted for library preparation and Illumina HiSeq sequencing. We identified 3094 differentially expressed genes (DEGs) in 13-HPODE-treated cells and 2862 DEGs in LA-treated cells relative to untreated cells. We show that 13-HPODE enhanced lipid metabolic pathways, including steroid hormone biosynthesis, PPAR signaling, and bile secretion, which alter lipid uptake and transport. 13-HPODE and LA treatments promoted detoxification mechanisms including cytochrome-P450. Conversely, both treatments suppressed oxidative phosphorylation. We also show that both treatments may promote absorptive cell differentiation and reduce proliferation by suppressing pathways involved in the cell cycle, DNA synthesis/repair and ribosomes, and enhancing focal adhesion. A qRT-PCR analysis of representative DEGs validated the RNA-seq analysis. This study provides insights into mechanisms by which 13-HPODE alters cellular processes and its possible involvement in mitochondrial dysfunction-related disorders and proposes potential therapeutic strategies to treat $\mathrm{LOOH}-$ related pathologies.
\end{abstract}

Keywords: lipid peroxidation; gene expression; metabolism

\section{Introduction}

Dietary lipids, including vegetable oils, contain different quantities of the most common dietary polyunsaturated fatty acid (PUFA), linoleic acid (LA), in the form of triglycerides, which are hydrolyzed by bile and lipases. This process releases large amounts of free fatty acids (FFAs), often in millimolar quantities, that are absorbed by intestinal cells [1]. Depending on processing (e.g., deep frying), the ingested lipids may contain varying quantities of peroxidized PUFAs and their decomposition products [2]. Dietary lipid peroxides (LOOHs) are broken down in the gut, resulting in the production of other lipid peroxidation products, such as epoxy ketones, and the release of peroxidized fatty acids (FAs) that reach the enterocytes, where they get absorbed [3]. It has been demonstrated that dietary LOOHs from overheated oils contribute to the presence of peroxidized FAs in the lipoproteins [4], which indicates that even though dietary LOOHs undergo a set of enzymatic digestion, peroxidized FAs reach the intestine and get absorbed. 
LOOHs have been strongly linked to disorders of the digestive system, including inflammatory bowel disease (IBD) and malignancy [5]. Studies have demonstrated that while $\mathrm{LOOH}$ is efficiently absorbed by the fully differentiated (Dif) intestinal epithelial cells and transported in the lymph, it is poorly taken up by undifferentiated cells $[3,6]$. In addition, it has been demonstrated that the uptake of oxidized FAs by Dif Caco-2 cells is dependent on the presence of brush borders and is comparable to the uptake of unoxidized FAs in Dif Caco-2 cells [3]. 13-hydroperoxyoctadecadienoic acid (13-HPODE) is decomposed by cells rapidly into aldehydes, including 4-hydroxynonenal (4-HNE) and oxononanoic acid (ONA), which are cytotoxic and cause the generation of reactive oxygen species (ROS). Previous studies have shown that $\mathrm{LOOH}$ caused oxidative stress and the loss of cellular integrity in the intestinal epithelium [7]. Peroxidized fat consumption has also been reported to cause pro-inflammatory changes in the intestine [8,9]. Iron/ascorbatemediated production of $\mathrm{LOOH}$ in Caco- 2 cells has been shown to result in activation of NF$\kappa \mathrm{B}$, which regulates inflammatory processes [10]. Dietary LOOHs have also been implicated in cardiovascular disease [3,11]. Previous studies also showed that peroxidized fat was carried in the chylomicrons [12], which was correlated with the peroxidized fat content in the diet [13] - these are believed to be re-packaged and distributed in the lipoproteins. The presence of peroxidized fat in the chylomicrons has been shown to increase the atherogenicity of dietary cholesterol [14] and promote the absorption of cholesterol [15].

The Caco-2 cell line is a human intestinal epithelial cell line that is derived from human colorectal adenocarcinoma [16]. Under certain cultivation conditions, Caco-2 cells differentiate into a cell monolayer that possesses absorptive features and brush borders resembling human enterocytes. This cell line has been widely used in studies involving cellular uptake, transport, and metabolism of drugs and food molecules, including lipids $[3,15,17]$. Using the Caco-2 cell line to study lipid transport and metabolism by intestinal epithelium is less challenging than using in vivo animal models [18]. Previous research has revealed that sub-cytotoxic levels of $\mathrm{LOOH}$ cause significant injury and mitogenic changes to Caco-2 cells, whereas higher concentrations of LOOH promote cell death $[19,20]$. LOOHs have also been suggested to induce redox imbalance and disruption of intestinal epithelial turnover [21]. Accordingly, the response of Caco-2 cells to $\mathrm{LOOH}$ depends on the amount of $\mathrm{LOOH}$ to which intestinal cells are exposed. In addition, $\mathrm{LOOH}$ reduced cell membrane fluidity and increased permeability in intestinal epithelial cells [22]; the latter of which is a reported effect in patients with IBD [23]. Changes in membrane fluidity and dynamics could affect several cellular processes [24], including lipid absorption by enterocytes and secretion into lacteals [25]. In addition, LOOH appeared to induce DNA damage as well [7].

A recently published study demonstrated similar results between Caco-2 cells treated with 13-HPODE and mice fed with 13-HPODE [26], which makes treatment of Caco-2 cells with 13-HPODE a good model of dietary LOOH intake. Thus, in this study, we used Caco-2 cells to investigate the effects of 13-HPODE, the most common dietary lipid peroxide, on the metabolic processes, cellular pathways, and phenotype of the intestinal epithelium. We generated gene expression profiles using RNA-seq to gain insights into how Caco-2 cells respond to 13-HPODE. We used these data to identify molecular mechanisms that may explain the contribution of lipid peroxidation to health conditions and their potential role in gut pathology. Here, we conducted RNA sequencing of Caco-2 cells treated with a specific $\mathrm{LOOH}$, 13-HPODE, a lipoxidase-derived product from LA, since LA is the most abundant dietary PUFA [27]. Bioinformatic analyses of the generated RNA-seq data provided valuable information on dysregulated genes and disrupted pathways in Caco-2 cells in response to 13-HPODE, the most common dietary LOOH. We compared the results obtained from 13-HPODE-treated cells with the gene expression profile of Caco-2 cells treated with LA, which represented non-peroxidized lipids. Treatment of Caco-2 cells with LA mimics the intake of vegetable oils such as soybean and canola oils and nuts as LA is the most common omega-6 PUFA in vegetable oils and in the Western diet [28]. In addition, comparable results were seen when intestinal culture cells were treated with pure linoleic acid or lipase-digested sesame oil [29]. Validation of RNA-seq results was carried 
out using qRT-PCR analysis, which showed consistent results with our RNA-seq data. In future works, these investigations could provide potential therapeutic strategies to treat diseases associated with the consumption of peroxidized linoleic acid.

\section{Materials and Methods}

\subsection{Cell Culture}

Caco-2 cells were purchased from American Type Culture Collection (ATCC) (Rockville, MD, USA). Cells were cultured in Dulbecco's modified Eagle's medium (DMEM; Invitrogen, Carlsbad, USA) supplemented with 15\% fetal bovine serum (FBS; Invitrogen, Carlsbad, USA), 2 mM L-glutamine (Invitrogen, Carlsbad, CA, USA), and 1\% penicillin-streptomycin (Invitrogen, Carlsbad, CA, USA). After attaining confluence, cells were cultured in the same medium supplemented with 7.5\% FBS and the same concentration of other constituents. Confluent cells were trypsinized using $0.25 \%$ Trypsin-EDTA solution (Thermo Fisher Scientific, Waltham, MA, USA). Caco-2 cells were seeded in 6-well plates and experiments were carried out on fully differentiated cells (Dif; Day-14).

\subsection{Preparation of Lipid Peroxide}

Stock solution of linoleic acid (LA) (Sigma \#W338001-25G, St. Louis, MO, USA) was prepared in ethanol, and LA $(200 \mu \mathrm{M})$ in phosphate-buffered saline (PBS; Invitrogen, Carlsbad, CA, USA) was prepared for LA treatment of cells. 13-hydroperoxyoctadecadienoic acid (13-HPODE) was freshly prepared in PBS as previously described [9,14,30]. Briefly, LA $(200 \mu \mathrm{M})$ in PBS ( $\mathrm{pH} 7.4)$ was oxidized with the addition of $10 \mathrm{U}$ soybean lipoxygenase (Sigma \#L6632-1MU), which can be easily miscible with the medium. Conjugated diene formation during oxidation was monitored by scanning the absorption between $200 \mathrm{~nm}$ and $300 \mathrm{~nm}$ using a spectrophotometer (Uvikon XL, Biotek Instruments, El Cajon, CA, USA), using PBS as the reference. The conversion of linoleic acid into its oxidized form was observed as an increase in the optical density at $234 \mathrm{~nm}$. Peroxide content was determined using a leucomethylene blue (LMB) assay [31]. The whole solution of the freshly prepared 13-HPODE was filter-sterilized to reduce the risk of contamination and used for the cell culture experiments within $2 \mathrm{~h}$ of preparation to minimize spontaneous peroxide decomposition.

\subsection{Treatment of Cells with 13-HPODE/LA}

As previously described [26], Dif Caco-2 cells were starved in serum-free medium for $3 \mathrm{~h}$ prior to treatment. Cells were treated with $100 \mu \mathrm{M}$ of either 13-HPODE or LA for $24 \mathrm{~h}$. Untreated control cells were maintained with equal amounts of PBS to match the treatments. After $24 \mathrm{~h}$ incubation, cells were rinsed with PBS and harvested into TRIzol for total RNA isolation. Experiments were run in triplicate.

\subsection{Total RNA Extraction and Quantification}

Cells were lysed directly in the 6-well culture plates using TRIzol reagent (Invitrogen, 15596026). Cell lysate was transferred to tubes and chloroform was added. The samples were vortexed and incubated at room temperature for $3 \mathrm{~min}$ then centrifuged at $12,400 \times g$ for $15 \mathrm{~min}$. The upper aqueous phase, containing RNA, was transferred into fresh tubes. Isopropyl alcohol was added to the samples and centrifuged for $10 \mathrm{~min}$ at $12,000 \times g$ to precipitate RNA from the aqueous phase. Total RNA was washed with ethanol at $7500 \times g$ for $5 \mathrm{~min}$ and air-dried for 2-3 min. RNA was resuspended in RNase-free water, then sample concentration, purity, and quality were determined using a NanoDrop spectrophotometer (Thermo Fisher Scientific, Waltham, MA, USA), which showed absorbance ratios of 1.8-2 at $260 \mathrm{~nm}$ and $280 \mathrm{~nm}$. Any co-extracted DNA was removed from RNA samples using the TURBO DNA-free kit (Invitrogen, AM1907, Carlsbad, CA, USA), following the manufacturer's instructions. 


\subsection{RNA-seq Library Preparation and Sequencing}

We isolated mRNA from total RNA samples using the NEBNext Poly(A) mRNA Magnetic Isolation Module (New England Biolabs, E7490S, Ipswich, MA, USA) with an approximate input of $500 \mathrm{ng}$ of total RNA per sample. RNA-seq libraries were prepared from mRNA samples using the NEBNext Ultra II Directional RNA Library Prep kit for Illumina (New England Biolabs, E7760S) according to the manufacturer's instructions, including NEBNext Sample Purification Bead cleanups to remove unincorporated primers and adapters. Samples were fragmented for $15 \mathrm{~min}$ at $94{ }^{\circ} \mathrm{C}$ to achieve a target fragment size of 200 base pairs (bp). Indexed adaptors for Illumina sequencing (New England Biolabs, E7710, E7730) were ligated to libraries through 8 cycles of PCR. Library quality was assessed using High Sensitivity D1000 reagents (Agilent Technologies, 5067-5585, Santa Clara, CA, USA) on a TapeStation 2200 instrument (Agilent Technologies, Santa Clara, CA, USA). Library concentrations were determined using the NEBNext Library Quant Kit for Illumina (New England Biolabs, E7630S) following the manufacturer's instructions. Three dilutions of each library were prepared $(1: 1000,1: 10,000,1: 100,000)$ and plated in triplicate on a 96-well qPCR plate along with manufacturer-supplied standards ( $20 \mu \mathrm{L}$ reactions). Concentration data were used to ensure equimolar pooling across libraries for multiplexing. The final library pool was checked for quality using the High Sensitivity D1000 ScreenTape assay, which showed good quality with a maximum peak size of $337 \mathrm{bp}$ (Figure S1), and sent to GENEWIZ (South Plainfield, NJ, USA) for sequencing (HiSeq4000 $2 \times 150 \mathrm{bp}$ ). The number of sequencing reads ranged between 48 and 79 million reads with a mean quality score $>37$.

\subsection{Sequence Data Processing}

The following pipeline was used to analyze the paired-end sequencing reads. We used FastQC (version v0.11.7) to check the quality of reads, which were all of good quality scores $>30$, and the presence of adapters or overrepresented sequences [32]. Trimmomatic (version 0.36) was used to remove adapters and poor-quality bases [33]. Hisat2 (version 2.1.0) was used to align the reads to a human reference genome (Ensembl/Genome Reference Consortium Human Build 38, GRCh38) [34]; all samples showed overall read alignment rates $>90 \%$. Then, FeatureCounts (version 1.5.0) was run to count the number of fragments mapped to a specific gene/exon [35]. We used DESeq2 (version 1.30.0), an $\mathrm{R}$-package which uses negative binomial distribution to model read counts, to identify differentially expressed genes (DEGs; adjusted $p<0.05$ ) between different groups [36]. Gene symbols were used from the Ensembl database.

\subsection{Enrichment Analyses}

Differentially expressed genes were evaluated further using gene ontology and enrichment analyses using the enrichGO function of the clusterProfiler (version 3.18.0) R package [37], and Generally Applicable Gene-set Enrichment (GAGE, version 2.40.0; also $\mathrm{R}$ package) [38], respectively. Gene ontology (GO) analysis was carried out by running the enrichGO function on the list of DEGs (adjusted $p<0.05$ ) (from DESeq2) in the treated cell group to identify enriched GO terms including biological processes, molecular functions, and cellular components. Pathway and gene set enrichment analyses (GSEA) were conducted by running the gage function on the list of DEGs and their log2 fold change scores. This generated a list of dysregulated Kyoto Encyclopedia of Genes and Genomes (KEGG) pathways, their $p$ values, and their direction (downregulated or upregulated).

\subsection{Validation via $q R T-P C R$}

RNA-seq results were technically confirmed via qRT-PCR using the same RNA samples used for the RNA-seq study. Fourteen representative DEGs were chosen to perform qRT-PCR for 13-HPODE-treated cells and eleven DEGs for LA-treated cells. SsoAdvanced ${ }^{\mathrm{TM}}$ Universal SYBR $^{\circledR}$ Green Supermix (BioRad, 1725271), $2.5 \mu \mathrm{M}$ of primer (forward and reverse each), and $0.1 \mathrm{ng}$ of cDNA was used in a $10 \mu \mathrm{L}$ PCR reaction. The 
protocol was set as $95^{\circ} \mathrm{C}$ for $30 \mathrm{~s}$ (initial denaturation), and 40 cycles of $95^{\circ} \mathrm{C}$ for $15 \mathrm{~s}$ (denaturation) and $60^{\circ} \mathrm{C}$ for $30 \mathrm{~s}$ (annealing/extension). GAPDH was used as a housekeeping gene. Relative mRNA expression levels were determined using the $\Delta \Delta \mathrm{Ct}$ method. A $t$-test was used to determine the statistical differences between the treated and untreated groups and the data were presented as means \pm SD. Primer sequences are provided in Table S1.

\section{Results}

We incubated Dif Caco-2 cells with $100 \mu \mathrm{M}$ of 13-HPODE or LA for $24 \mathrm{~h}$. We chose these concentrations as the proximal intestine is exposed to millimolar concentrations of FA and our preliminary results showed little or no cytotoxicity $[3,15]$. The control (untreated) group was maintained in PBS. Experiments were run in triplicate (details are explained in the Section 2). Following RNA extraction, processing, and sequencing, differential gene expression and enrichment analyses were carried out. Principal component analysis showed that replicate samples demonstrated similarity in gene expression with respect to treatment, and there was good separation between untreated and treated groups (Figure S2). The log ratio vs. mean average (MA) plots (Figure S3) show that differentially expressed genes (DEGs; red dots) with a large mean expression across untreated and treated cell groups call for significance.

\subsection{3-HPODE-Treated Caco-2 Cells}

\subsubsection{Differential Gene Expression}

Using DESeq2, we identified 3094 DEGs (adjusted $p<0.05$ ) between 13-HPODEtreated cells and untreated cells (Table S2); 1692 genes were downregulated and 1402 genes were upregulated in 13-HPODE-treated cells relative to untreated cells. Among the upregulated genes were genes involved in lipid metabolism such as PLIN2, FABP1, CPT1A, and PCK1, which are involved in PPAR signaling, which on one hand has shown to exert anti-inflammatory effects in obesity, diabetes, and cardiovascular disease [39], but on the other hand, could have both anti-proliferative and carcinogenic effects [40]. CPT1A and ACADVL, which are involved in mitochondrial beta-oxidation of fatty acids, and PDK4 and PCK1, which have a role in lipid and glucose metabolism, were upregulated. Induction of these genes may promote both fat metabolism and gluconeogenesis. Genes involved in stress response, such as CREB3L3 and NDRG1, were also induced. Although we observed reduced expression of glutathione peroxidases GPX1 and GPX7, there was upregulation of GCLC, which is essential for glutathione (GSH) synthesis, which might indicate increased GSH contents. Reduced glutathione peroxidase activity has been linked with colon cancer [41], cardiovascular disease [42], obesity, and insulin resistance [43]. We also observed upregulation of some nuclear factor erythroid 2-related factor 2 (Nrf2) target genes that play a role in the antioxidant defense systems such as HMOX1, CAT, UGT2B4, and TXNRD1. Several solute carrier (SLC) transporters were upregulated, such as SLC26A3, a chloride transporter; SLC38A4, an amino acid transporter; and SLC5A3, a myo-inositol transporter, indicating changes in substrate transport across the cell membrane. In addition, SLC transporters have been implicated in various diseases, including IBD and metabolic diseases [44,45]. Other upregulated genes included COL7A1, which forms fibrils between epithelial cell basement membrane and extracellular matrix, and PDZK1, which regulates epithelial cell surface proteins and is involved in cholesterol metabolism. Among the downregulated genes were $O D C 1$ and $P O L D 2$, which are important for polyamine synthesis and DNA replication, respectively. GPCPD1, which is involved in glycerophospholipid biosynthesis, and PTGES2, which is involved in prostaglandin E synthesis, were also downregulated. 13-HPODE treatment also caused the reduction of NOX1, a NADPH oxidase that generates ROS, as well as DKK1, which is an inhibitor of Wnt signaling [46]. Figure 1 shows the top 50 DEGs in 13-HPODE-treated Caco-2 cells compared to untreated cells. 


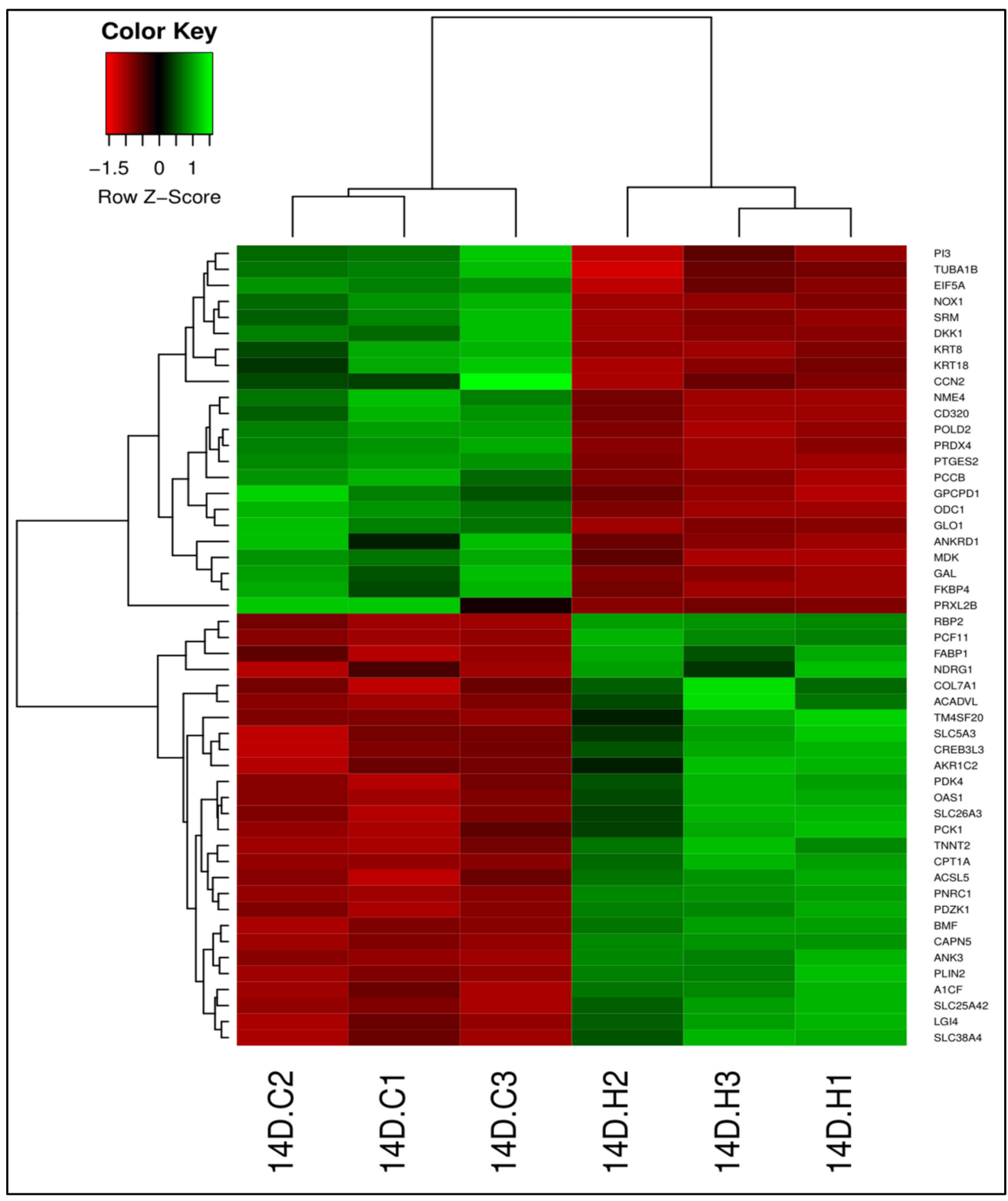

Figure 1. Differential gene expression between 13-HPODE-treated cells and untreated control cells. Heatmap shows the top 50 differentially expressed genes (DEGs; adjusted $p<0.05$ ) in 13-HPODEtreated Caco-2 cells (14D.H1, 14D.H2, and 14D.H3) compared to untreated control cells (14D.C1, 14D.C2, and 14D.C3). Green, upregulated; red, downregulated.

\subsubsection{Gene Ontology}

Gene ontology analysis was performed using the enrichGO function of the clusterProfiler R-package. The results revealed the enrichment of diverse biological processes (adjusted $p<0.05$ ) involved in translation, ribosome biogenesis, RNA processing, response to hypoxia and oxidative stress, mitochondrial translation, and gene expression. Purine nucleoside monophosphate, alcohol, and amino acid metabolic processes (Figure 2), as well as carbohydrate and lipid metabolic processes (not shown), were also enriched due to 13-HPODE treatment.

Among the enriched molecular functions (adjusted $p<0.05$ ) in Caco-2 cells treated with 13-HPODE were ATPase, oxidoreductase, antioxidant, electron transfer, RNA polymerase I, and helicase activities. Additionally, coenzyme, carboxylic acid, heat shock protein, and cadherin and chaperone binding functions were enriched (Figure S4). 


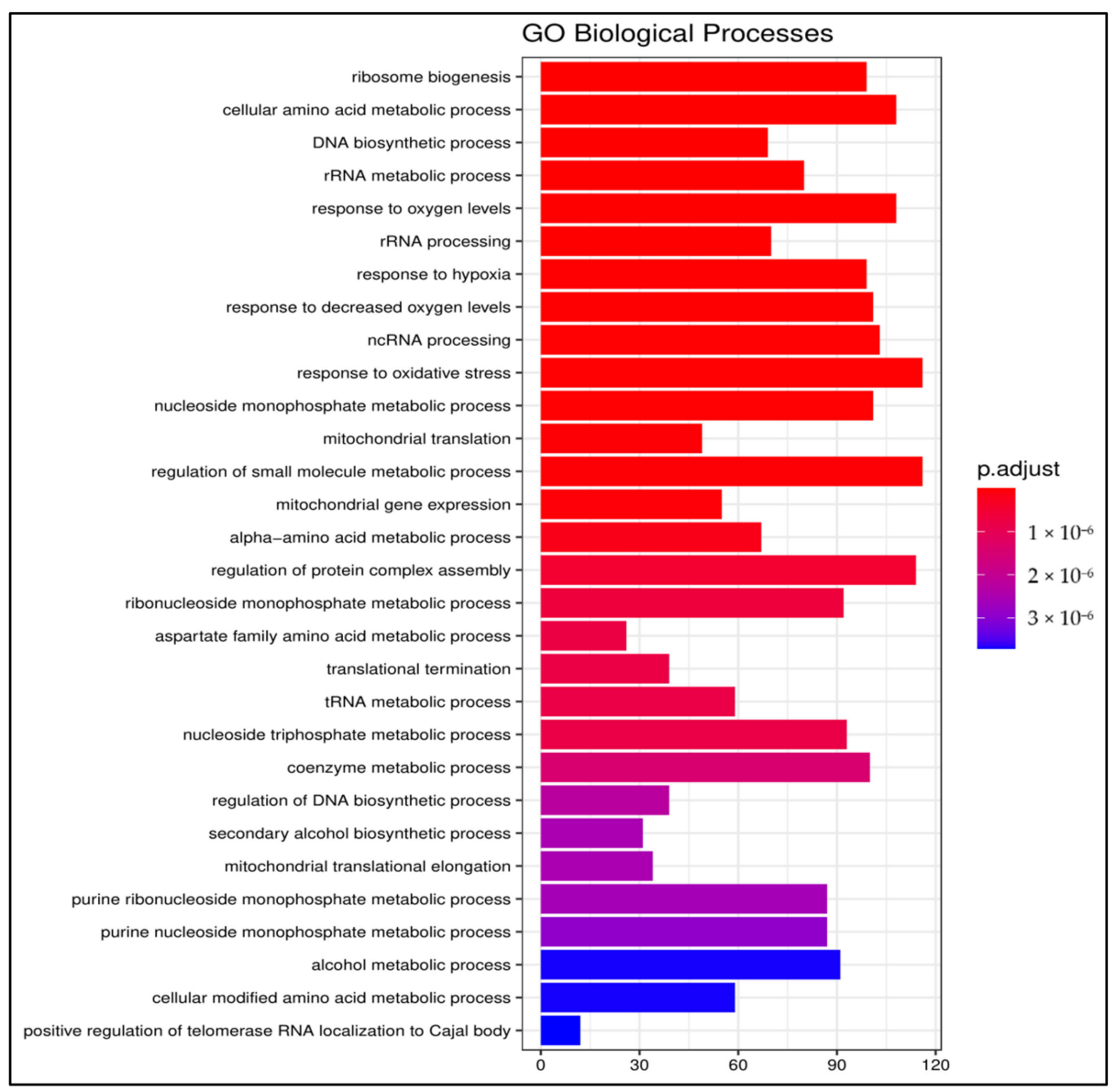

Figure 2. Biological process enrichment upon treating Caco-2 cells with 13-HPODE. Top enriched gene ontology (GO) biological processes in 13-HPODE-treated differentiated Caco-2 cells relative to untreated control cells (adjusted $p<0.05$ ).

The enriched cellular components (adjusted $p<0.05$ ) included the mitochondrial inner membrane, matrix, ribosome, and protein complex, as well as ribosomal subunits, the spliceosomal complex, focal adhesion, and the cell-substrate adherens junction (Figure S5). The brush border and apical plasma membrane were also enriched (not shown).

\subsubsection{Pathway Enrichment Analysis}

We used the gage R-package to perform pathway enrichment analysis (Table 1). Among the top upregulated KEGG pathways $(p<0.05)$ in 13-HPODE-treated cells, relative to untreated cells, were steroid hormone biosynthesis, bile secretion, and protein digestion and absorption. We also observed upregulation of importantly relevant pathways such as metabolism of xenobiotics by cytochrome P450, focal adhesion, and PPAR signaling, but with slightly higher $p$ values.

Among the downregulated pathways $(p<0.05)$ observed for 13-HPODE-treated cells, relative to untreated cells, were spliceosome, RNA transport, ribosome biogenesis, and RNA polymerase pathways, as well as purine and pyrimidine metabolism. Oxidative stress can cause base modification and DNA damage [47]. Pathways of cell cycle, DNA replication, and excision repair appeared to be suppressed as well. The proteasomal pathway involved in proteolytic degradation of intracellular protein was also downregulated. The results also showed a reduction in the oxidative phosphorylation pathway. 
Table 1. Pathway enrichment analysis in 13-HPODE-treated Caco-2 cells. Pathway enrichment demonstrates upregulated and downregulated Kyoto Encyclopedia of Genes and Genomes (KEGG) pathways in 13-HPODE-treated Caco-2 differentiated cells relative to untreated cells.

\begin{tabular}{cc}
\hline KEGG Pathway (Upregulated) & $p$-Value \\
\hline I00140 Steroid hormone biosynthesis & 0.018 \\
I04976 Bile secretion & 0.029 \\
I04974 Protein digestion and absorption & 0.029 \\
I00980 Metabolism of xenobiotics by cytochrome P450 & 0.062 \\
I04510 Focal adhesion & 0.069 \\
I03320 PPAR signaling pathway & 0.199 \\
\hline KEGG Pathway (Downregulated) & $p$-Value \\
I03040-Spliceosome & 0.0001 \\
I00240-Pyrimidine metabolism & 0.0004 \\
I03008-Ribosome biogenesis in eukaryotes & 0.0005 \\
I03013-RNA transport & 0.002 \\
I00190-Oxidative phosphorylation & 0.003 \\
I04110-Cell cycle & 0.004 \\
I00230-Purine metabolism & 0.006 \\
I03420-Nucleotide excision repair & 0.009 \\
I03020-RNA polymerase & 0.009 \\
I03050-Proteasome & 0.014 \\
I03030-DNA replication & 0.018 \\
I04120-Ubiquitin-mediated proteolysis & 0.030 \\
I03410-Base excision repair & 0.031 \\
I03010-Ribosome & 0.034 \\
\hline
\end{tabular}

\subsection{LA-Treated Caco-2 Cells}

\subsubsection{Differential Gene Expression}

We identified 2862 DEGs (adjusted $p<0.05$ ) in LA-treated cells compared to untreated cells (Table S3); 1179 genes were upregulated and 1683 genes were downregulated in LA-treated cells. As in 13-HPODE-treated cells, PDZK1 was induced. TTN, which has been reported as a key component of intestinal epithelial brush borders [48], was also upregulated. Among the downregulated genes in LA-treated cells were RGCC, a cell cycle regulator; CYTOR, a long non-coding RNA that enhances proliferation; and CEACAM6, which is a cell adhesion molecule that promotes tumor progression. HMGCS1, involved in cholesterol biosynthesis; $D D X 47$, involved in spliceosome and ribosomal RNA processing; EIF5A, a translation elongation factor; and ODC1 were suppressed as well. Reduction in the expression of these genes may indicate reduced cell proliferation upon LA treatment. Genes involved in the regulation of metabolic pathways were also downregulated, such as INSIG1, which regulates lipid synthesis and glucose homeostasis, and the RPIA gene, involved in carbohydrate metabolism. In addition, genes that are involved in the regulation of cellular fate and processes were suppressed, such as JUN, a transcription factor that regulates gene expression; DUSP4, dual specificity phosphatase of mitogen-activated protein kinase; and $D K K 1$. Other downregulated genes included PI3, a peptidase inhibitor (antimicrobial); $S L C 2 A 1$, a glucose transporter; and SLC20A1, a phosphate transporter [46]. Figure 3 illustrates the top 50 DEGs in LA-treated Dif Caco-2 cells compared to untreated cells. 


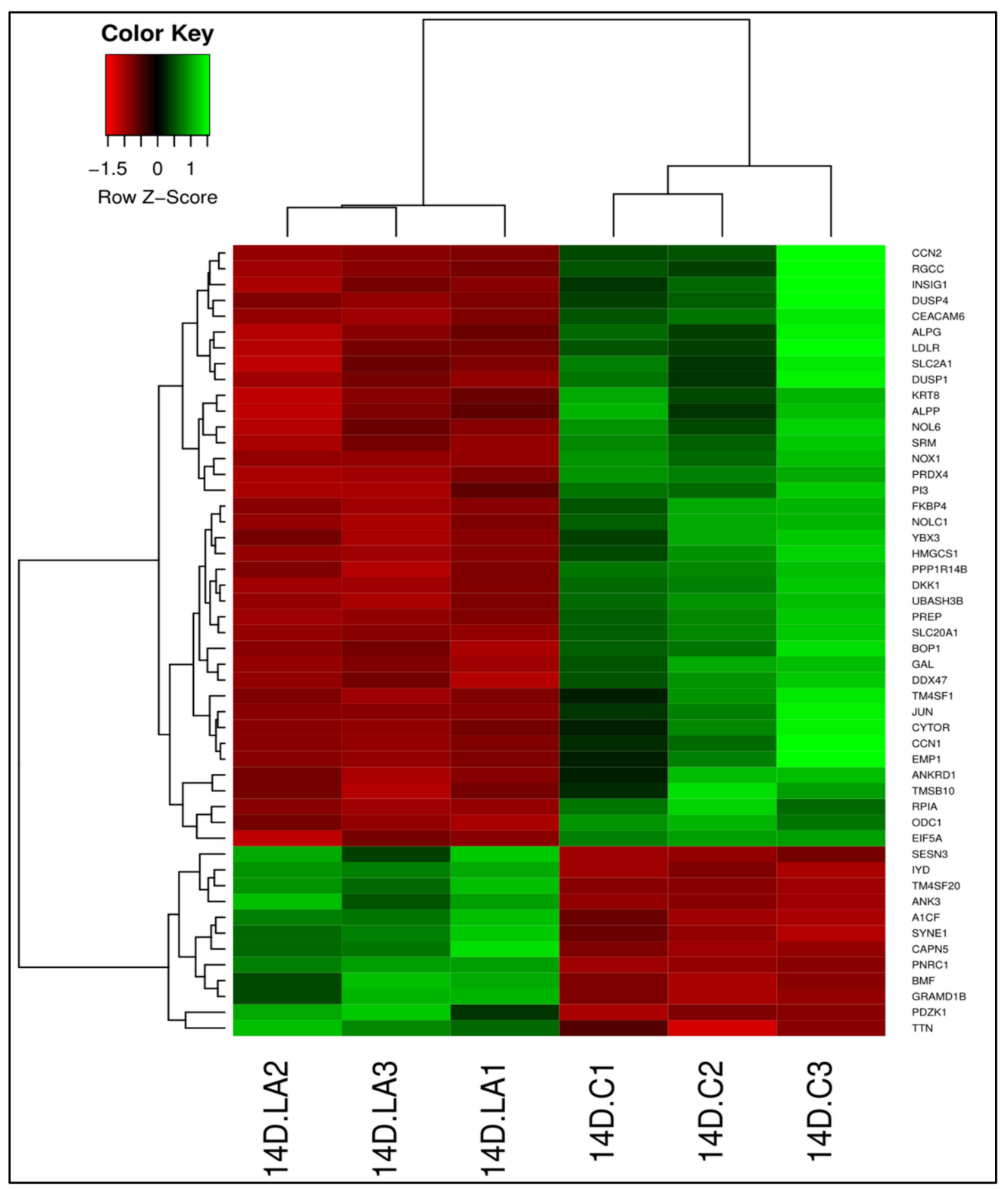

Figure 3. Differential gene expression between linoleic acid (LA)-treated cells and untreated control cells. Heatmap shows the top 50 DEGs (adjusted $p<0.05$ ) in LA-treated Caco-2 cells (14D.LA1, 14D.LA2, and 14D.LA3) compared to untreated cells (14D.C1, 14D.C2, and 14D.C3). Green, upregulated; red, downregulated.

\subsubsection{Gene Ontology}

Among the enriched biological processes in LA-treated cells relative to untreated cells were ribosome biogenesis; rRNA and ncRNA processing; small molecule, amino acid, and coenzyme metabolic processes; ribonucleoprotein complex assembly; and mitochondrial translation and gene expression. In addition, the response to decreased oxygen levels, purine nucleotide biosynthesis, DNA duplex unwinding, anion transport, and carbohydrate metabolic processes were enriched in LA-treated cells (Figure 4). 


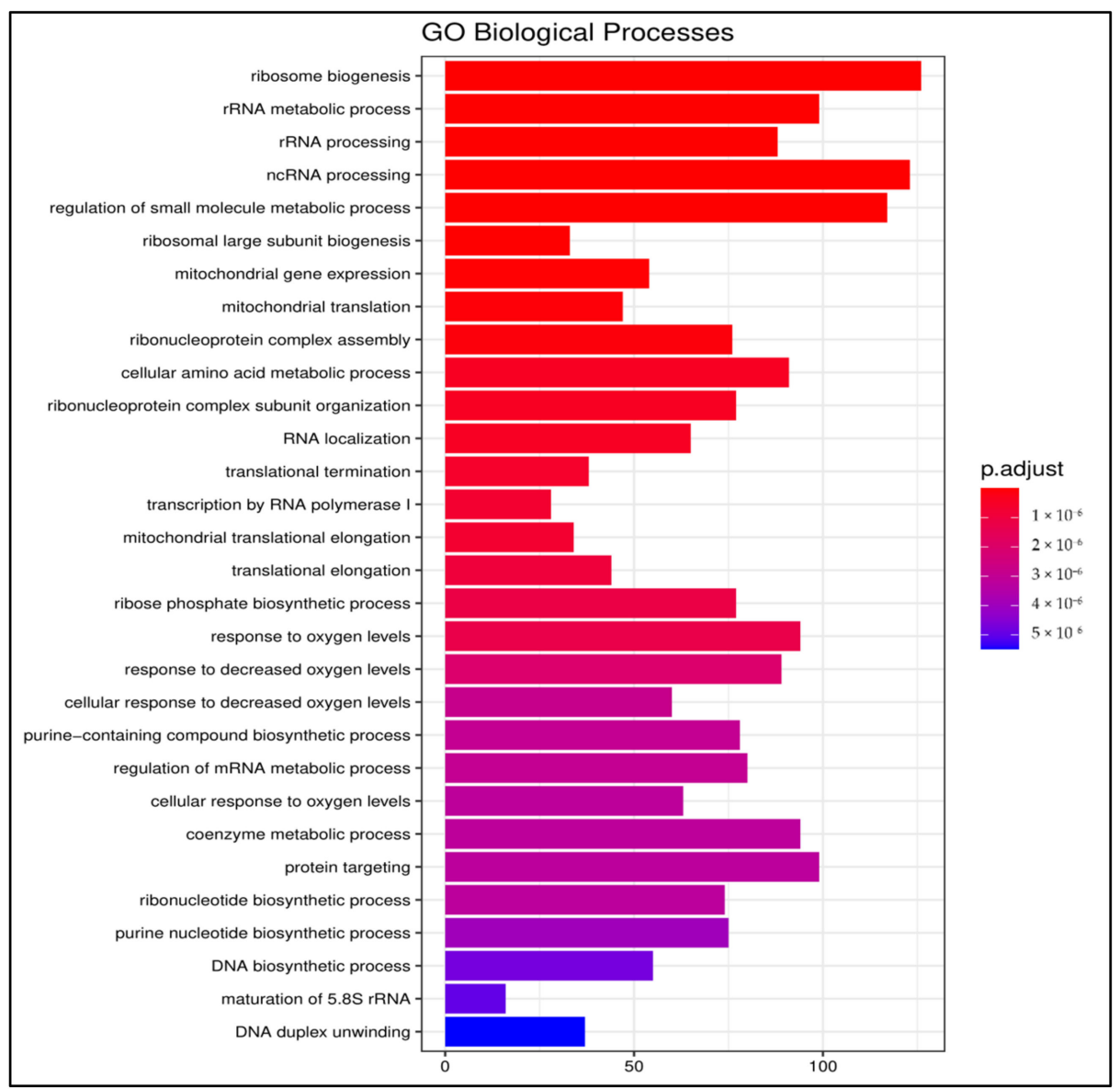

Figure 4. Biological process enrichment upon treating Caco-2 cells with LA. Top enriched GO biological processes in LA-treated differentiated Caco-2 cells relative to untreated cells (adjusted $p<0.05$ ).

Molecular functions enriched in LA-treated Dif Caco-2 cells included organic acid transmembrane transporter activity, helicase, ligase, RNA polymerase, and ATPase activities. Moreover, ribonucleoprotein complex, cadherin, ATPase, coenzyme, organic acid, cell adhesion molecule, and RNA binding were also enriched (Figure S6).

Among the enriched cellular components in LA-treated cells relative to untreated cells were preribosome, and organellar and mitochondrial ribosomes. Mitochondrial outer/inner membrane and matrix, cellular and organellar outer membrane, and envelop lumen components were also enriched. In addition, complexes such as proteasome, spliceosome, and endopeptidase complexes were enriched in LA-treated cells, as well as focal adhesion and adherens junctions (Figure S7). The brush border and apical plasma membrane were also enriched (not shown).

\subsubsection{Pathway Enrichment Analysis}

Linoleic acid treatment of Dif Caco-2 caused upregulation $(p<0.05)$ of metabolic processes including retinol, xenobiotic, and drug metabolism by cytochrome P450, relative to untreated cells. The protein digestion and absorption pathway was also upregulated.

Among the pathways downregulated $(p<0.05)$ in LA-treated cells, relative to untreated cells, were ribosome biogenesis, spliceosome, RNA transport, and RNA polymerase pathways. As in 13-HPODE-treated cells, purine and pyrimidine metabolism, oxidative phosphorylation, proteasome, cell cycle, and excision repair pathways were also suppressed in LA-treated cells. Toll-like receptor signaling, which activates innate immunity, was downregulated (Table 2). 
Table 2. Pathway enrichment analysis in LA-treated Caco-2 cells. Pathway enrichment demonstrates upregulated and downregulated KEGG pathways in LA-treated Caco-2 differentiated cells relative to untreated cells.

\begin{tabular}{cc}
\hline KEGG Pathway (Upregulated) & $p$-Value \\
\hline I00830-Retinol metabolism & 0.010 \\
I04080-Neuroactive ligand-receptor interaction & 0.017 \\
I00980-Metabolism of xenobiotics by cytochrome P450 & 0.017 \\
I00982-Drug metabolism—cytochrome P450 & 0.039 \\
I04974_-Protein digestion and absorption & 0.047 \\
\hline KEGG Pathway (Downregulated) & $p$-Value \\
\hline I03008-Ribosome biogenesis in eukaryotes & 0.0001 \\
I03040-Spliceosome & 0.0004 \\
I03013-RNA transport & 0.0007 \\
I00240-Pyrimidine metabolism & 0.0009 \\
I00190-Oxidative phosphorylation & 0.016 \\
I03020-RNA polymerase & 0.017 \\
I03050-Proteasome & 0.020 \\
I00230-Purine metabolism & 0.037 \\
I04110-Cell cycle & 0.038 \\
I03420-Nucleotide excision repair & 0.043 \\
I04620-Toll-like receptor signaling pathway & 0.045 \\
\hline
\end{tabular}

\subsection{Differential Gene Expression between 13-HPODE-Treated and LA-Treated Cells}

We identified 291 DEGs (adjusted $p<0.05$ ) between 13-HPODE-treated and LAtreated cells (Figure S8; Table S4). We found that genes involved in PPAR signaling showed higher expression levels in 13-HPODE-treated cells compared to LA-treated cells. Among those genes were CPT1A, which is involved in FA oxidation; PLIN2, which coats lipid droplets; ACSL5 and FABP1, which are involved in FA transport; HMGCS2, which is involved in ketogenesis; and PCK1. Upregulation of the latter gene and PDK4 could promote gluconeogenesis, as mentioned earlier. These results might suggest that 13HPODE is a more potent activator of PPAR signaling than LA, although both oxidized and unoxidized LA have been shown in previous studies to activate PPARs [30,49]. This also indicates a significant effect of 13-HPODE on glucose and lipid metabolism and transport as PPAR signaling has been shown to regulate metabolic processes including FA and glucose metabolism, as well as cell proliferation and differentiation [50,51]. Additional genes involved in FA oxidation, including SLC25A20 and ACADVL, were upregulated in 13-HPODE-treated cells compared to LA-treated cells. On the other hand, G6PD, which plays a role in FA and cholesterol biosynthesis, also showed higher expression in 13HPODE-treated cells relative to LA-treated cells. Lower expression of APOH, which has an atheroprotective role by inhibiting the uptake of oxidized low density lipoprotein (LDL) [52], was observed in 13-HPODE-treated cells relative to LA-treated cells. We observed increases in the expression of genes involved in defense mechanisms in 13HPODE-treated relative to LA-treated cells. Among these were CREB3L3; ABCG2, which is a xenobiotic transporter that extrudes toxins from cells; and CYP2B6 and AKR1B1, which metabolize xenobiotics and aldehydes.

We observed increased expression of genes that play a role in detoxification in LAtreated cells relative to 13-HPODE-treated cells. Among these were EPHX2, which is involved in xenobiotic metabolism; ADH6, which metabolizes alcohols and lipid peroxidation products; and ALDH6A1, which plays a role in protective detoxification of aldehydes. Sucrase-isomaltase gene, SI, which is involved in dietary carbohydrate digestion and is expressed in the intestinal brush border, showed upregulated expression in LA-treated cells relative to 13-HPODE-treated cells. Interestingly, cell adhesion molecules CEACAM1/M6/M5, which are considered biomarkers of tumor progression and metastasis, showed low expression levels in LA-treated cells relative to 13-HPODE-treated cells. 


\subsection{Validation of RNA-Seq Results}

RNA-seq results were verified via qRT-PCR. Different gene sets were selected for validation in each treatment according to the differential gene expression and pathway analysis in the treated groups relative to the untreated group. Fourteen representative DEGs were chosen to perform qRT-PCR for 13-HPODE-treated cells and eleven DEGs for LA-treated cells. Genes involved in PPAR signaling, as well as mitochondrial beta oxidation, such as PLIN2, FABP1, and CPT1A, were upregulated in 13-HPODE-treated cells relative to untreated cells (Figure 5a,c). PDK4 and PCK1 genes, which play a role in the regulation of lipid and glucose metabolism, were also upregulated in 13-HPODE-treated cells, suggesting enhanced gluconeogenesis in these cells relative to untreated cells (Figure 5d,e). CREB3L3, inflammatory response gene, and $B A A T$, involved in bile acid synthesis, were upregulated by 13-HPODE compared to untreated cells (Figure 5f,g). 13-HPODE treatment was associated with increased expression of COL7A1, a collagen type VII alpha 1 chain, and VIL1 genes (Figure $5 \mathrm{~h}, \mathrm{i}$ ), involved in focal adhesion and the brush border cytoskeleton, respectively, which might indicate enhanced cell differentiation. Aldo/keto reductase AKR1C2, which is involved in steroid hormone and bile acid synthesis, was induced by 13-HPODE (Figure 5j). CYP2B6 was also upregulated in 13-HPODE-treated cells (Figure 5k). 13-HPODE reduced the expression of NADPH oxidase NOX1 (Figure 51). Other genes with reduced expression when treated with 13-HPODE treatment included DKK1 and RPP40, which are involved in Wnt signaling and rRNA processing, respectively (Figure $5 \mathrm{~m}, \mathrm{n}$ ).

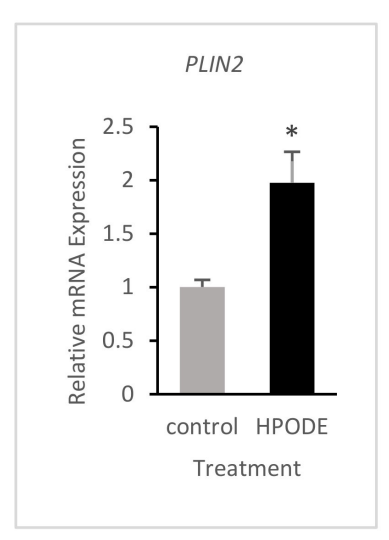

(a)

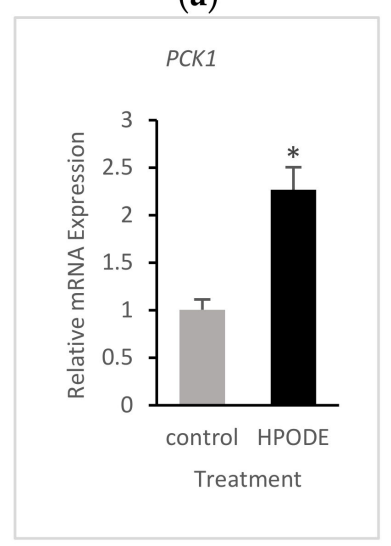

(e)

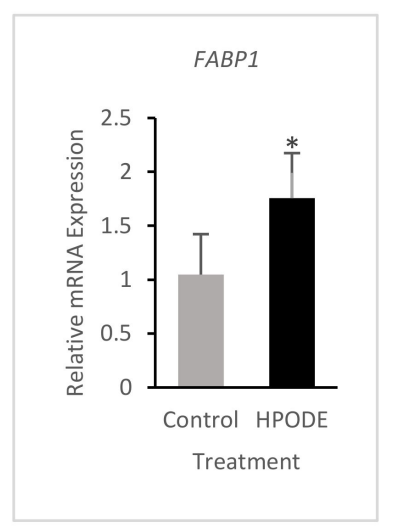

(b)

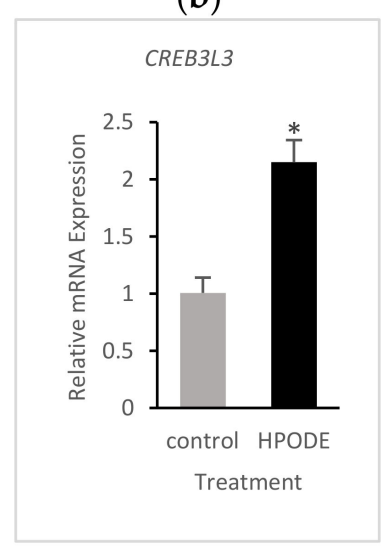

(f)

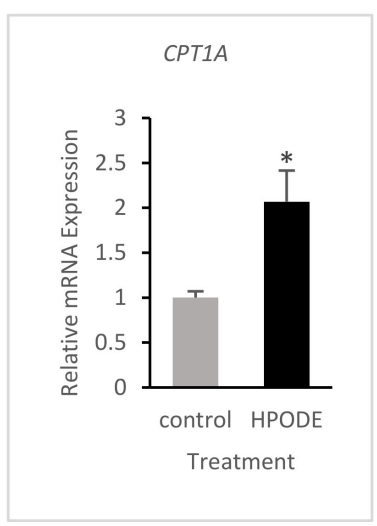

(c)

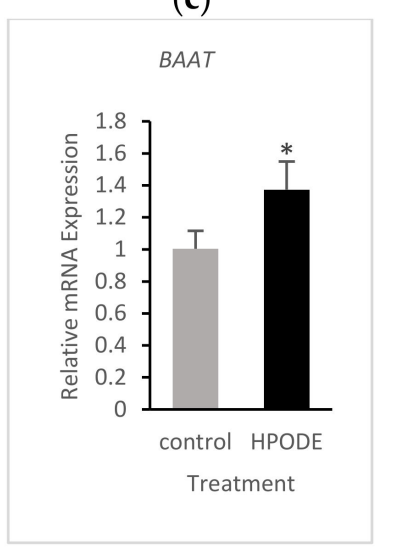

(g)

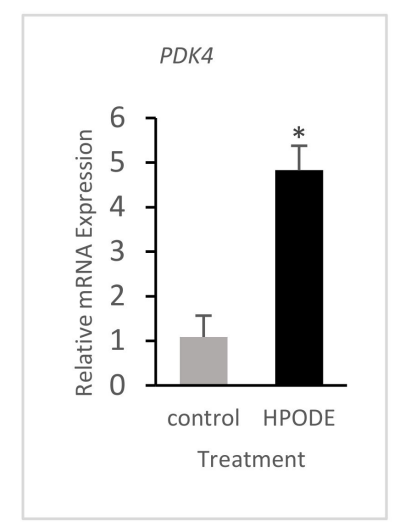

(d)

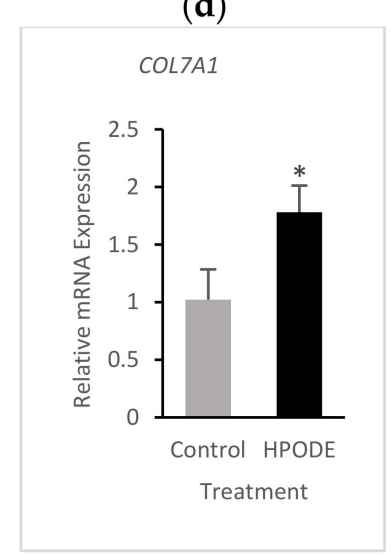

(h)

Figure 5. Cont. 


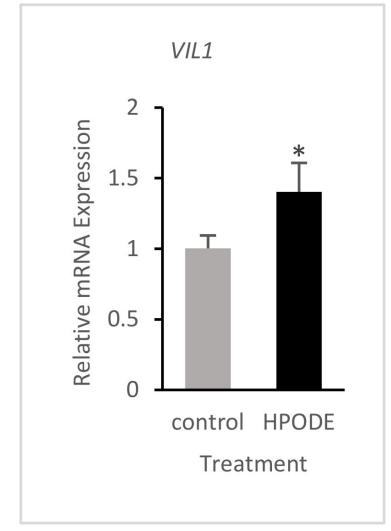

(i)

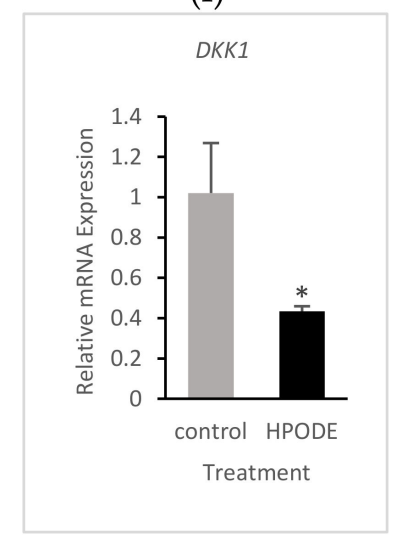

$(\mathbf{m})$

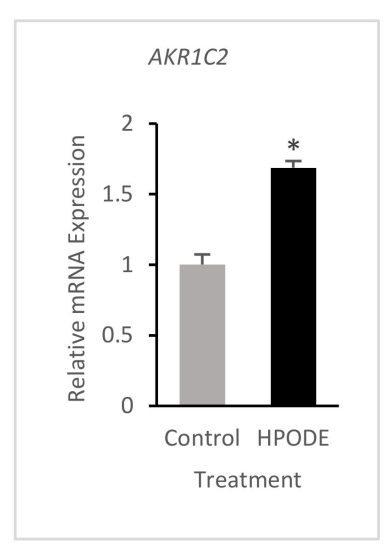

(j)

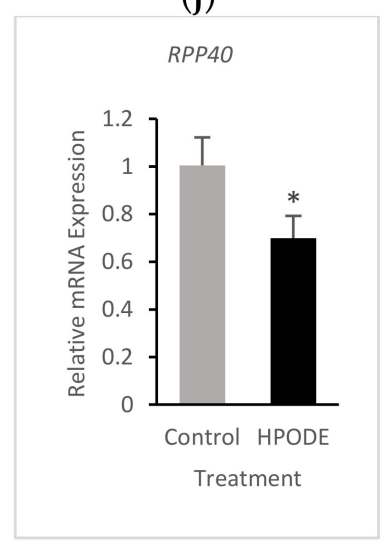

(n)

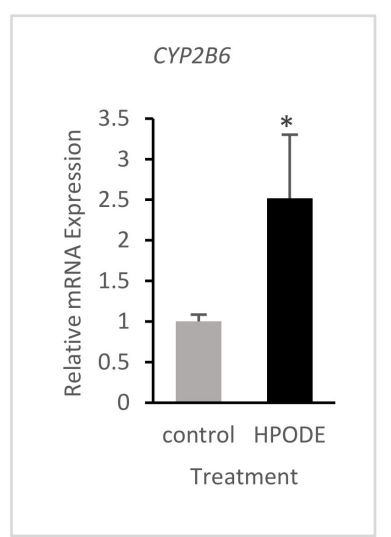

$(\mathbf{k})$

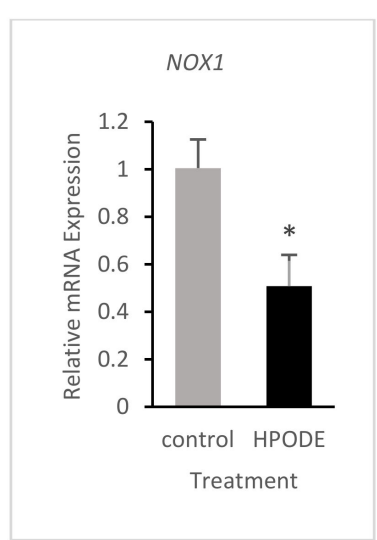

(1)

Figure 5. Quantitative Real-time PCR validation of RNA-seq results in 13-HPODE-treated cells (a-n). qRT-PCR of representative DEGs from RNA-seq data. Relative mRNA expression of genes is presented in 13-HPODE-treated (HPODE) Caco-2 cells with statistical significance of * $p<0.05$ compared to untreated (control) cells. Results were normalized to GAPDH.

The relative expression of PCK1 and DKK1 in LA-treated cells was similar to that of 13HPODE-treated cells when both were compared to untreated cells (Figure 6a,b). In addition, CYP2C9, a cytochrome P450 mono-oxygenase; UGT2B4, a detoxifying UDP glucuronosyltransferase; and COL7A1 were upregulated in LA-treated cells relative to untreated cells (Figure 6c-e). Reduced expression of RGCC and ODC1 could be attributable to reduced proliferative potential and enhanced differentiation (Figure 6f,g). LA treatment led to downregulation of INSIG1 and TOMM5 genes, which might affect metabolic processes and mitochondrial function (Figure 6h,i). DUSP4, as well as cell adhesion molecule CEACAM6, was reduced in LA-treated cells as well, which could be a protective response against tumor progression (Figure 6j,k). These results are consistent with the RNA-seq data. 


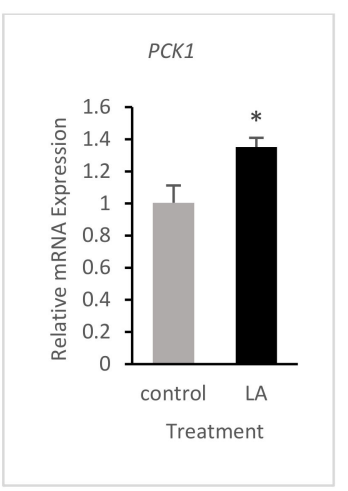

(a)

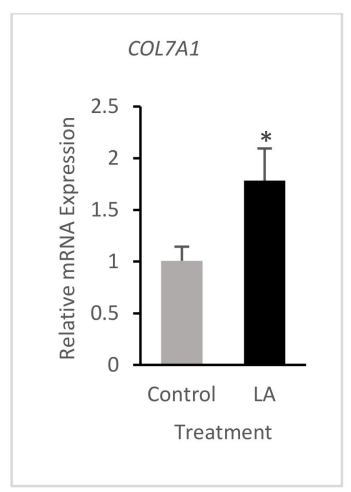

(e)

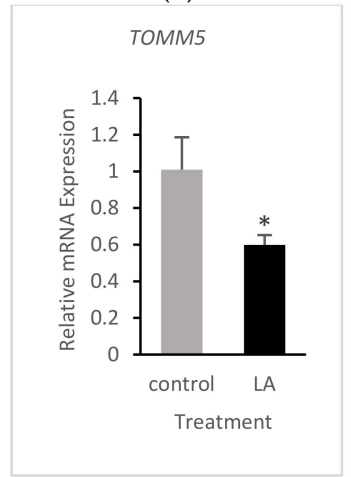

(i)

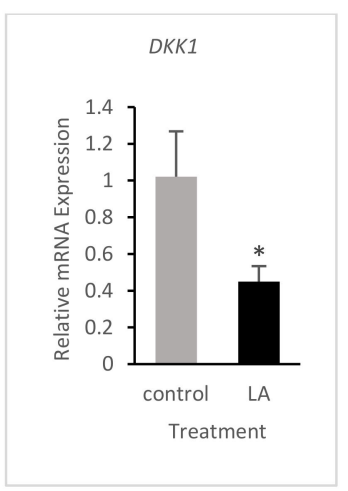

(b)

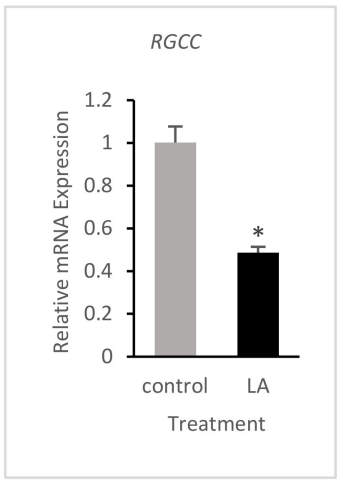

(f)

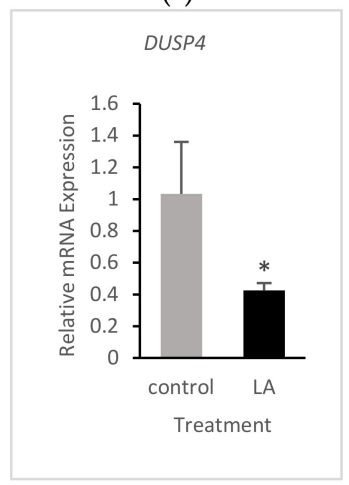

(j)

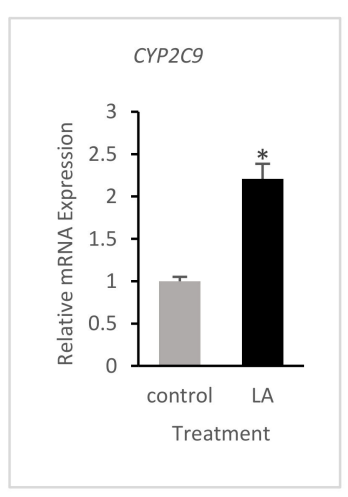

(c)

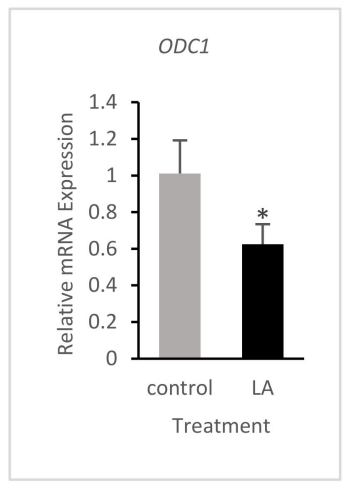

(g)

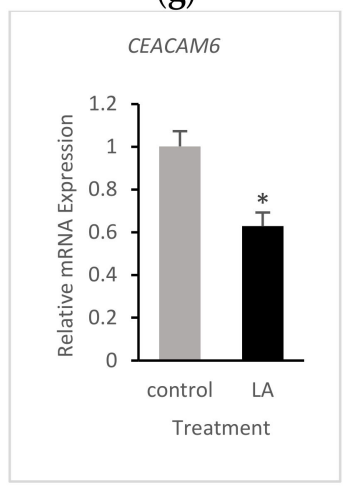

(k)

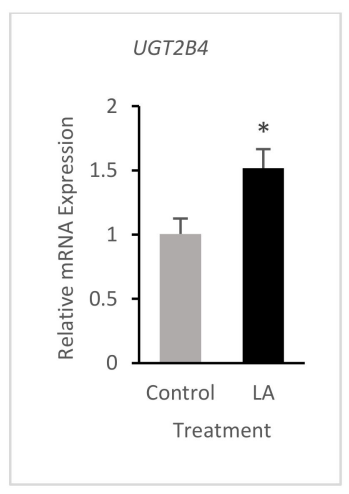

(d)

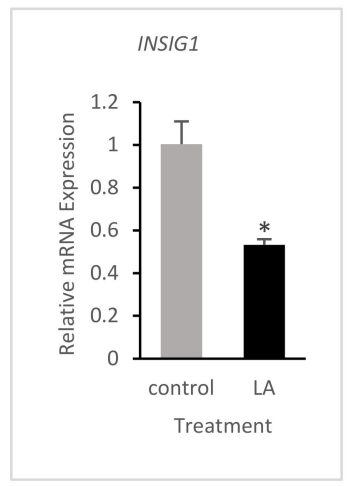

(h)

Figure 6. Quantitative Real-time PCR validation of RNA-seq results in LA-treated cells (a-k). qRT-PCR of representative DEGs from RNA-seq data. Relative mRNA expression of genes is presented in LA-treated (LA) Caco-2 cells with statistical significance of * $p<0.05$ compared to untreated (control) cells. Results were normalized to GAPDH.

\section{Discussion}

LA, an essential PUFA consumed through the human diet, is an important cellular component. It is a precursor of lipid peroxides including hydroxyoctadecadienoic acid (HODE), the reduced form of 13-HPODE [53]. LOOHs have been linked to several pathological conditions including cardiovascular disease, degenerative disease, and malignancy [54]. Diet is a major source of $\mathrm{LOOH}$, and dietary peroxides are absorbed, transported, and incorporated into lipoproteins that carry these lipids into cells and tissues. We used mRNA sequencing to investigate how the most common dietary LOOH, 13-HPODE, modulates the gene expression profile in Dif Caco- 2 cells, the results of which could provide insights into changes in the physiological processes of cells and the mechanisms by which 13-HPODE may contribute to disease. Treating Caco-2 cells with 13-HPODE, a peroxidized LA, significantly alters metabolic and signaling pathways, as well as different cellular processes. 
In the current study, we have demonstrated that 13-HPODE increased the expression of aldo/keto reductases, such as $A K R 1 C 2$, that are essential for steroid hormone synthesis. Studies have reported the ability of the intestine to synthesize steroid hormones $[55,56]$. Steroid hormones have been shown in a previous study to play a role in maintaining the intestinal epithelial barrier [57]; on the other hand, they may not only cause inhibition of T-cell response [55], but may also promote immune function [58], which might contribute to inflammatory disease. It has been reported previously that oxidized LA can induce steroid hormone synthesis in rat and human adrenal cells $[59,60]$. Upregulated aldo/keto reductases might indicate that 13-HPODE could be converted to aldehydic products in intestinal epithelial cells and promote the detoxification of reactive carbonyl species and the reduction of 4-HNE, which may enhance adaptive response [61]. In addition, oxidized LA metabolites have been linked to obesity and shown to induce synthesis of steroids [62]. Oxidized LA may possess bile acid activity and the ability to form mixed micelles with fat, which increases cholesterol solubilization and absorption [15]. Although bile secretion occurs in the liver, our pathway analysis showed that this pathway was enriched in Caco-2 cells treated with 13-HPODE. We found that the BAAT gene, which is responsible for bile acid conjugation that enhances fat solubility, was upregulated in 13-HPODEtreated cells. This could propose another mechanism by which 13-HPODE increases lipid solubilization. A previous study demonstrated that bile secretion in response to a highfat diet could injure the intestinal epithelium and that secondary bile acids produced by intestinal flora may induce tumor formation [63]; this might be studied as an indirect mechanism by which $\mathrm{LOOH}$ could contribute to malignancy. On the other hand, the BAAT gene was not differentially expressed in LA-treated cells relative to untreated cells. It is also worth mentioning that both 13-HPODE and LA treatments enhanced the expression of $A P O B$, apolipoprotein $\mathrm{B}$, which is a major component of chylomicron and LDL, along with $A 1 C F$, a complementation factor of ApoB mRNA editing enzyme complex essential for the generation of ApoB48, which promotes dietary fat absorption [64].

Although upregulation of the PPAR signaling pathway upon treating cells with 13HPODE had a slightly higher $p$-value of 0.1 , several downstream genes involved in fatty acid and lipid homeostasis were among the top differentially upregulated genes (adjusted $p<0.05)$ in 13-HPODE-treated cells relative to untreated cells. Among those were PLIN2, which forms the lipid droplet coat, and FABP1, which may promote cholesterol uptake and protect against oxidative stress caused by LOOH [65]. HMGCS2, which is involved in ketogenesis and has been found to promote cellular differentiation of Caco-2 cells [66], was also upregulated. CPT1A and PCK1 were also among the differentially upregulated genes of PPAR signaling which may indicate promoted fatty acid oxidation, as well as gluconeogenesis. As oxidized LA is considered a ligand that activates PPAR signaling, which plays multiple roles ranging between metabolism, anti-inflammatory, and antiand pro-carcinogenic effects, PPAR signaling should be considered a powerful form of crosstalk between 13-HPODE and peroxidized lipid-related diseases and should be studied further. Moreover, CREB3L3, a transcription factor that works with PPAR $\alpha$ in an autoloop manner [67] and is involved in unfolded stress response and lipid metabolism, was upregulated in 13-HPODE-treated cells. Although we observed upregulation of several genes involved in PPAR signaling and FA oxidation, including PLIN2, PCK1, and CPT1A in LA-treated cells, the expression of these genes appeared to be higher in 13-HPODEtreated cells compared to LA-treated cells. This suggests that 13-HPODE may have a more powerful effect on PPAR signaling and FA oxidation than non-peroxidized LA. We also observed higher expression of G6PD, required for FA and cholesterol biosynthesis, and a lower expression of atheroprotective $A P O H$ in 13-HPODE-treated cells compared to LA-treated cells, which could propose a mechanism by which LOOHs contribute to the development of cardiovascular disease.

Our results indicate that 13-HPODE may enhance detoxification by cytochrome P450 enzymes, which play a role in the metabolism of ingested drugs and toxins, and in the synthesis of steroid hormones, bile acids, and some other fats $[68,69]$. Upregulated 
CYP1B1/2C9/2B6 may be a protective response against 13-HPODE treatment as it is considered a harmful metabolite of oxidized LA. in addition to aldo/keto reductases' function in steroid hormone synthesis, they are also involved in xenobiotic metabolism by cytochrome P450, as well as bile acid synthesis and transport [70,71]. In the current study, LA also induced cytochrome P450 enzymes, including CYP2C9. Moreover, LA treatment resulted in higher expression of alcohol and aldehyde dehydrogenases ADH6 and ALDH6A1 in LA-treated cells compared to 13-HPODE-treated cells, which could indicate a protective effect of LA against lipid peroxidation products, including aldehydes. This may also suggest that LA could undergo oxidation in the intestinal cells to which the cells respond by enhancing the detoxification mechanism.

As 13-HPODE comes in contact with the cell membrane, we could expect oxidation of vitamin E (Tocopherol; TP) and the formation of tocopheryl quinone (TQ), which is antiandrogenic [72] and has an apoptotic effect that has been reported to inhibit colon cancer cell growth [73]. Moreover, since we observed that 13-HPODE caused downregulation of glutathione peroxidases GPX1 and GPX7 and upregulation of the catalytic subunit of glutamate-cysteine ligase, GCLC, essential for glutathione (GSH) synthesis, the cells could accumulate GSH. The latter has previously shown to convert the tocopheroxyl radical back to TP to maintain its scavenging effect on reactive oxygen species (ROS) via oxidation of vitamin $\mathrm{E}$, thus preventing further lipid oxidation and inhibiting cell proliferation [74]. TP regeneration has been also linked to thioredoxin reductase [75], which was upregulated in 13HPODE-treated cells. TP has been shown to reduce chemokines in human aortic endothelial cells (HAECs) [76], and has been shown to reduce expression of the chemokine CXCL1 [77]. In our study, we observed downregulation of CXCL1, CXCL8 (IL-8), and CCL20 chemokines in 13-HPODE-treated cells. It has been suggested that tocopheryl hydroquinone (TQH) is a more powerful antioxidant than TQ [78,79]. In our study, upregulation of cytochrome p450 oxidoreductase (POR gene) [78], which is reported to catalyze the formation of TQH, was observed in 13-HPODE-treated cells. TQ has been shown to induce apoptosis via activation of the caspase 3 cascade and to reduce anti-apoptotic Bcl-2 [80]. In this context, we observed upregulation of $C A S P 3$ and a number of $\mathrm{Bcl}$ family members that have apoptotic activity, such as BMF, BCL2L11, and BNIP5 (this gene has not been studied yet), and downregulation of the anti-apoptotic BAG1 gene in 13-HPODE cells. This is consistent with a recently published study [26] which demonstrated reduced cell viability on annexin V staining of Caco-2 cells treated with $100 \mu \mathrm{M}$ 13-HPODE.

Although we did not observe expression changes in members of activator protein-1 (AP-1) or NFE2L2 (Nrf2), we did observe upregulation of some target genes that play a role in the antioxidant defense systems, including HMOX1, CAT, UGT2B4, and TXNRD1, as well as downregulation of SOD1 in 13-HPODE-treated cells. This indicates that a degree of the antioxidant protective response was enhanced by 13-HPODE. Moreover, we observed increased expression of FOXO3 and FOXO4 transcription factors, by which 13-HPODE could modulate insulin signaling and the antioxidant response and could trigger apoptosis [81]. In addition to CAT, another FOXO-regulated gene, CDKN1A (p21), which inhibits cell proliferation in response to DNA damage, was also upregulated in 13-HPODE-treated cells.

13-HPODE treatment caused the downregulation of events that have been reported to be reduced during Caco-2 cell differentiation [82]. Among the pathways downregulated due to 13-HPODE treatment were RNA transport, spliceosome, and translation machinery. In parallel with this, events of the cell cycle, DNA replication and repair, and protein degradation, including the proteasomal pathway, were also suppressed. Under culture conditions, Caco-2 cells undergo extensive genetic reprogramming during differentiation and lose their tumorigenic phenotype [16]. This genetic reprogramming includes downregulation of genes involved in cell cycle progression, DNA replication/repair, as well as genes involved in RNA splicing/transport and protein degradation, which indicates reduced proliferation; this was reported by Mariadason et al. [82]. Hence, downregulation of these events upon treating the cells with 13-HPODE or LA, as we observed in the current study, may suggest a further 
reduction in the proliferative potential and a shift towards differentiation. Among downregulated genes in both 13-HPODE-treated and LA-treated cells were POLD2, MCM7, and $P C N A$, which are involved in DNA replication; $C D C 25 A$, which is important for cell cycle progression; and RPP40 and EIF5A, which are involved in RNA processing and translation. On the other hand, tumor suppressor genes including APC, KLF4, and FOXO4 were upregulated in 13-HPODE-treated cells. In LA-treated cells, we observed downregulation of the proto-oncogene, JUN, and upregulation of the tumor suppressor genes KLF7 and FOXO4. Interestingly, LA treatment caused a reduction in the expression of cell adhesion molecules CEACAM1/M5/M6, which are considered biomarkers of tumor progression [83]; this may also indicate reduced proliferation. $\mathrm{LOOH}$-derived oxidative stress can cause base modification and DNA damage [47] due to the formation of DNA adducts via interaction between nucleotides and malondialdehyde (MDA), hence the protective response of DNA synthesis reduction was required to prevent further DNA damage by $\mathrm{LOOH}$ end-products [84]. Despite the various studies on $\mathrm{LOOH}$-induced DNA damage, the mechanism by which LOOHs reduce DNA synthesis needs to be further investigated.

In support of shifting towards differentiation, the focal adhesion pathway, which is involved in cell motility, differentiation, and other processes, was enhanced ( $p$-value 0.06 ) in 13-HPODE-treated cells relative to untreated cells. Among the related induced genes was COL7A1. In the intestine, this pathway plays a role in epithelial barrier homeostasis and repair and tight junction organization [85]. This may indicate enhanced cellular differentiation, which promotes the development of brush borders, as evidenced by the upregulated VIL1 gene in 13-HPODE-treated cells. In addition to the upregulation of VIL1, the sucrase-isomaltase gene, SI, which is another marker of intestinal differentiation [86] showed elevated expression in LA-treated cells compared to 13-HPODE-treated cells, indicating enhanced cellular differentiation. Furthermore, we observed upregulation of retinol metabolism in LA-treated cells, relative to untreated cells, which has been shown to play a role in intestinal epithelial cell processes including growth and differentiation [87]. In addition, UGT2B4, a detoxifying enzyme that plays a role in the retinol metabolic pathway, was detected and upregulated in LA-treated cells.

Our results showed a reduction in the oxidative phosphorylation pathway in both 13-HPODE- and LA-treated cells relative to untreated cells. Disrupted oxidative phosphorylation has been previously reported in mice fed with oxidized linoleic acid [88]. Moreover, mitochondrial components including membranes and matrix were among the top enriched GO terms in both 13-HPODE- and LA-treated cells, relative to untreated cells, which indicates the significant effect of 13-HPODE and LA on mitochondrial function. The TOMM5 gene, which is a translocase of the outer mitochondrial membrane, was downregulated in both treatments. It has been reported that PUFAs can cause a change in mitochondrial membrane composition and organization that leads to increased production of ROS, which in turn causes peroxidation of membrane phospholipids and mitochondrial dysfunction [89].

Toll-like receptor (TLR) signaling was downregulated in LA-treated Caco-2 cells relative to untreated cells, which supports the previously reported inhibitory effect of PUFAs on TLR activation and inflammatory gene expression [90]. Specifically, n-3 PUFAs appeared to be more powerful inhibitors of TLR signaling than $n-6$ PUFAs [91]. There was a relative similarity in the data results between LA- and 13-HPODE-treated cells, suggesting the possibility of LA being oxidized in the intestinal epithelium, which has been previously reported [92] (Table 3). 
Table 3. Comparative differential gene expression. Comparison of differential expression ( $\uparrow$ upregulation or $\downarrow$ downregulation) of selected genes in the two treatment cell groups relative to the untreated cell group.

\begin{tabular}{ccc}
\hline Gene & 13-HPODE-Treated & LA-Treated \\
\hline DKK1 & $\downarrow \downarrow 3$ & $\downarrow \downarrow$ \\
CPT1A & $\uparrow \uparrow 3$ & $\uparrow 2$ \\
PLIN2 & $\uparrow \uparrow$ & $\uparrow$ \\
ODC1 & $\downarrow 2$ & $\downarrow$ \\
CREB3L3 & $\uparrow \uparrow$ & $\uparrow$ \\
FABP1 & $\uparrow \uparrow$ & $\uparrow$ \\
PDK4 & $\uparrow \uparrow$ & $\uparrow$ \\
PCK1 & $\uparrow \uparrow$ & $\uparrow$ \\
COL7A1 & $\uparrow \uparrow$ & $\uparrow$ \\
NOX1 & $\downarrow$ & $\downarrow$ \\
AKR1C2 & $\uparrow \uparrow$ & $\uparrow$ \\
SOS1 & $\uparrow$ & $\uparrow$ \\
BAAT & $\uparrow$ & $\mathrm{n}$ \\
CYP2B6 & $\uparrow \uparrow$ & $\uparrow$ \\
CYP2C9 & $\uparrow$ & $\uparrow$ \\
INSIG1 & $\mathrm{n}$ & $\downarrow$ \\
DDIT4 & $\uparrow$ & $\uparrow$ \\
DUSP4 & $\downarrow$ & $\downarrow \downarrow$ \\
UGT2B4 & $\downarrow$ & $\uparrow$ \\
TXNRD1 & $\uparrow$ & $\mathrm{n}$ \\
HMOX1 & $\uparrow$ & $\mathrm{n}$ \\
GSTP1 & $\uparrow X L 1$ & $\mathrm{n}$ \\
GPX1 & $\uparrow$ & $\downarrow$ \\
FOXO4 & $\uparrow$ & $\downarrow$ \\
POLD2 & $\downarrow$ & $\uparrow$ \\
ADH6 & $\downarrow$ & $\downarrow$ \\
\hline COM & $\downarrow$ & $\downarrow$ \\
\hline
\end{tabular}

${ }^{1} \mathrm{n}$ represents not differentially expressed (adjusted $\left.p>0.05\right) .{ }^{2}$ Single arrow $(\uparrow, \downarrow)$ represents differentially expressed (DE; adjusted $p<0.05) .{ }^{3}$ Double arrows $(\uparrow \uparrow, \downarrow \downarrow)$ represent DE with more pronounced effect.

\section{Conclusions}

The results of our transcriptomic profiling of Caco-2 cells carried out under standard in vitro conditions shed light on the response of intestinal epithelial cells to 13-HPODE or LA in terms of gene expression and pathway enrichment. The results presented in this study suggest that the most common dietary peroxidized lipid, 13-HPODE, may, on the one hand, enhance bile acid conjugation, which alters lipid uptake and might contribute to intestinal injury. On the other hand, 13-HPODE may affect multiple pathways of lipid metabolism including steroid hormone synthesis, which might affect intestinal barrier and immune function; and PPAR signaling, which alters fatty acid and glucose metabolism, energy production, and mitochondrial function leading to alteration of gut physiology. In addition, 13-HPODE as well as LA may have the ability to promote the antioxidant response and detoxification by cytochrome P450 in intestinal epithelial cells. Moreover, both treatments could reduce proliferative potential and could play a role in the absorptive cell differentiation and survival fates as they might suppress pathways involved in the cell cycle, DNA synthesis/repair, and enhance focal adhesion pathways. While similar effects could be seen in liver cells, it is conceivable that dietary peroxidized LA could have an impairment effect on energy production and lipid storage. In conclusion, this in vitro study using Caco-2 cells provides insights into the physiological changes that might occur in the intestinal epithelium upon exposure to 13-HPODE and the possible mechanisms by which it contributes to disease. Future directions of this research include studying the response of Caco-2 cells to $\mathrm{LOOH}$ using an experimental setting that simulates in vivo intestinal environment, such as the INFOGEST method [93]. 
Supplementary Materials: The following are available online at https://www.mdpi.com/2304 -8158/10/2/314/s1, Figure S1: Library quality assessment. Complementary DNA library pool quality assessment using High Sensitivity D1000 ScreenTape assay showed good quality library with a maximum peak size of $337 \mathrm{bp}$. Figure S2. Principal component analysis (PCA). PCA plot visualizes sample-to-sample distances between untreated and 13-hydroperoxyoctadecadienoic acid (HPODE)-treated (a) or linoleic acid (LA)-treated (b) Caco-2 cells showing similarity with respect to treatment and good separation between untreated and treated groups. Figure S3: Log ratio vs. mean average (MA) plot. MA plots show DEGs (red dots; adjusted $p<0.05$ ) between untreated Caco-2 cells and (a) 13-hydroperoxyoctadecadienoic acid (HPODE)-treated, or (b) linoleic acid (LA)-treated Caco- 2 cells. $x$-axis represents the mean expression across untreated and treated cell groups; $y$-axis represents the $\log 2$ fold change between untreated and treated groups. Figure S4: Molecular function enrichment upon treating Caco-2 cells with 13-HPODE. Top enriched GO molecular functions in 13-HPODE-treated differentiated Caco-2 cells relative to untreated cells (adjusted $p<0.05$ ). Figure S5: Cellular component enrichment upon treating Caco-2 cells with 13-HPODE. Top enriched GO cellular components in 13-HPODE-treated differentiated Caco-2 cells relative to untreated cells (adjusted $p<0.05$ ). Figure S6: Molecular function enrichment upon treating Caco-2 cells with LA. Top enriched GO molecular functions in LA-treated differentiated Caco-2 cells relative to untreated cells (adjusted $p<0.05$ ). Figure S7: Cellular component enrichment upon treating Caco-2 cells with LA. Top enriched GO cellular components in LA-treated differentiated Caco-2 cells relative to untreated cells (adjusted $p<0.05$ ). Figure S8: Differential gene expression between 13-HPODE-treated and LA-treated cells. Heatmap shows the top 50 DEGs (adjusted $p<0.05$ ) between 13-HPODE-treated Caco-2 cells (14D.H1, 14D.H2, and 14D.H3) and LA-treated cells (14D.LA1, 14D.LA2, and 14D.LA3). Green, upregulated; red, downregulated. Table S1: Primer sequences. Forward and reverse primer sequences used in quantitative RT-PCR. Table S2: Differential gene expression results of DESeq2 $\mathrm{R}$ package in 13-HPODE-treated cells. Differentially expressed genes (DEGs; adjusted $p<0.05$ ) in 13-HPODE-treated Caco-2 cells (14D.H1, 14D.H2, and 14D.H3) compared to untreated control cells (14D.C1, 14D.C2, and 14D.C3). Table S3: Differential gene expression results of DESeq2 R package in LA-treated cells. DEGs (adjusted $p<0.05$ ) in LA-treated Caco-2 cells (14D.LA1, 14D.LA2, and 14D.LA3) compared to untreated cells (14D.C1, 14D.C2, and 14D.C3). Table S4: Differential gene expression between 13-HPODE-treated and LA-treated cells. DEGs (adjusted $\mathrm{p}<0.05$ ) between 13-HPODE-treated Caco-2 cells (14D.H1, 14D.H2, and 14D.H3) and LA-treated Caco-2 cells (14D.LA1, 14D.LA2, and 14D.LA3).

Author Contributions: All authors have contributed substantially to the work reported. Conceptualization, N.F., S.Y. and S.P.; methodology, N.F., S.Y., S.P., A.F. and C.A.N.; software, N.F. and S.Y.; validation, N.F., S.Y. and S.P.; formal analysis, N.F. and S.Y.; investigation, N.F., S.Y., A.F. and C.A.N.; resources, N.F., S.Y., S.P., A.F. and C.A.N.; data curation, N.F. and S.Y.; writing-original draft preparation, N.F., S.Y. and S.P.; writing-review and editing, N.F., A.F., C.A.N., S.Y. and S.P.; visualization, N.F., S.Y. and S.P.; supervision, N.F., A.F., S.Y. and S.P.; project administration, N.F., A.F., C.A.N., S.Y. and S.P.; funding acquisition, S.Y. and S.P. All authors have read and agreed to the published version of the manuscript.

Funding: This research received no external funding.

Institutional Review Board Statement: Not applicable.

Informed Consent Statement: Not applicable.

Data Availability Statement: All sequence files and metadata are available at NCBI under BioProject accession PRJNA682114. https:/ / www.ncbi.nlm.nih.gov/bioproject/?term=PRJNA682114.

Acknowledgments: N.F. acknowledges graduate funding support from King Abdulaziz University, Jeddah, Saudi Arabia.

Conflicts of Interest: The authors declare no conflict of interest.

\section{References}

1. Pan, X.; Hussain, M.M. Gut triglyceride production. Biochim. Biophys. Acta Mol. Cell Biol. Lipids 2012, 1821, 727-735. [CrossRef] [PubMed]

2. Lise Halvorsen, B.; Blomhoff, R. Determination of lipid oxidation products in vegetable oils and marine omega-3 supplements. Food Nutr. Res. 2011, 55, 5792. [CrossRef] [PubMed] 
3. Penumetcha, M.; Khan, N.; Parthasarathy, S. Dietary oxidized fatty acids: An atherogenic risk? J. Lipid Res. 2000, 41, 1473-1480. [CrossRef]

4. Staprans, I.; Rapp, J.H.; Pan, X.M.; Feingold, K.R. The effect of oxidized lipids in the diet on serum lipoprotein peroxides in control and diabetic rats. J. Clin. Investig. 1993, 92, 638-643. [CrossRef]

5. Sottero, B.; Rossin, D.; Poli, G.; Biasi, F. Lipid Oxidation Products in the Pathogenesis of Inflammation-related Gut Diseases. Curr. Med. Chem. 2018, 25, 1311-1326. [CrossRef]

6. Staprans, I.; Pan, X.M.; Miller, M.; Rapp, J.H. Effect of dietary lipid peroxides on metabolism of serum chylomicrons in rats. Am. J. Physiol. Liver Physiol. 1993, 264, G561-G568. [CrossRef]

7. Wijeratne, S.S.K.; Cuppett, S.L. Lipid Hydroperoxide Induced Oxidative Stress Damage and Antioxidant Enzyme Response in Caco-2 Human Colon Cells. J. Agric. Food Chem. 2006, 54, 4476-4481. [CrossRef]

8. Bhaskar, N.; Narasimhulu, C.A.; Keewan, E.; Rohr, M.; Parthasarathy, S. Proinflammatory Properties of Peroxidized Fat May Contribute to the Etiology of Crohn's Disease. J. Med. Food. 2019, 22, 162-169. [CrossRef]

9. Rohr, M.; Narasimhulu, C.A.; Keewan, E.; Hamid, S.; Parthasarathy, S. The dietary peroxidized lipid, 13-HPODE, promotes intestinal inflammation by mediating granzyme B secretion from natural killer cells. Food Funct. 2020, 11, 9526-9534. [CrossRef]

10. Bernotti, S.; Seidman, E.; Sinnett, D.; Brunet, S.; Dionne, S.; Delvin, E.; Levy, E. Inflammatory reaction without endogenous antioxidant response in Caco-2 cells exposed to iron/ascorbate-mediated lipid peroxidation. Am. J. Physiol. Liver Physiol. 2003, 285, G898-G906. [CrossRef]

11. Staprans, I.; Pan, X.-M.; Rapp, J.H.; Feingold, K.R. The role of dietary oxidized cholesterol and oxidized fatty acids in the development of atherosclerosis. Mol. Nutr. Food Res. 2005, 49, 1075-1082. [CrossRef] [PubMed]

12. Staprãns, I.; Rapp, J.H.; Pan, X.M.; Kim, K.Y.; Feingold, K.R. Oxidized lipids in the diet are a source of oxidized lipid in chylomicrons of human serum. Arter. Thromb. A J. Vasc. Biol. 1994, 14, 1900-1905. [CrossRef] [PubMed]

13. Staprans, I.; Rapp, J.H.; Pan, X.M.; Feingold, K.R. Oxidized lipids in the diet are incorporated by the liver into very low density lipoprotein in rats. J. Lipid Res. 1996, 37, 420-430. [CrossRef]

14. Khan-Merchant, N.; Penumetcha, M.; Meilhac, O.; Parthasarathy, S. Oxidized Fatty Acids Promote Atherosclerosis Only in the Presence of Dietary Cholesterol in Low-Density Lipoprotein Receptor Knockout Mice. J. Nutr. 2002, 132, 3256-3262. [CrossRef] [PubMed]

15. Penumetcha, M.; Khan-Merchant, N.; Parthasarathy, S. Enhanced solubilization and intestinal absorption of cholesterol by oxidized linoleic acid. J. Lipid Res. 2002, 43, 895-903. [CrossRef]

16. Stierum, R.; Gaspari, M.; Dommels, Y.; Ouatas, T.; Pluk, H.; Jespersen, S.; Vogels, J.; Verhoeckx, K.; Groten, J.; Van Ommen, B. Proteome analysis reveals novel proteins associated with proliferation and differentiation of the colorectal cancer cell line Caco-2. Biochim. Biophys. Acta Proteins Proteom. 2003, 1650, 73-91. [CrossRef]

17. Hussain, M.M. Intestinal lipid absorption and lipoprotein formation. Curr. Opin. Lipidol. 2014, 25, 200-206. [CrossRef] [PubMed]

18. Nauli, A.M.; Whittimore, J.D. Using Caco-2 Cells to Study Lipid Transport by the Intestine. J. Vis. Exp. 2015, e53086. [CrossRef] [PubMed]

19. Cepinskas, G.; Kvietys, P.R.; Aw, T.Y. w3-Lipid peroxides injure CaCo-2 cells: Relationship to the development of reduced glutathione antioxidant systems. Gastroenterology 1994, 107, 80-86. [CrossRef]

20. Wang, T.-G.; Gotoh, Y.; Jennings, M.H.; Rhoads, C.A.; Aw, T.Y. Lipid hydroperoxide-induced apoptosis in human colonic CaCo-2 cells is associated with an early loss of cellular redox balance. FASEB J. 2000, 14, 1567-1576. [CrossRef]

21. Gotoh, Y.; Noda, T.; Iwakiri, R.; Fujimoto, K.; Rhoads, C.A.; Aw, T.Y. Lipid peroxide-induced redox imbalance differentially mediates CaCo-2 cell proliferation and growth arrest. Cell Prolif. 2002, 35, 221-235. [CrossRef] [PubMed]

22. Rohr, M.W.; Narasimhulu, C.A.; Rudeski-Rohr, T.A.; Parthasarathy, S. Negative Effects of a High-Fat Diet on Intestinal Permeability: A Review. Adv. Nutr. 2020, 11, 77-91. [CrossRef] [PubMed]

23. DeMeo, M.T.; Mutlu, E.A.; Keshavarzian, A.; Tobin, M.C. Intestinal Permeation and Gastrointestinal Disease. J. Clin. Gastroenterol. 2002, 34, 385-396. [CrossRef] [PubMed]

24. Spector, A.A.; Yorek, M.A. Membrane lipid composition and cellular function. J. Lipid Res. 1985, 26, 1015-1035. [CrossRef]

25. Wang, B.; Rong, X.; Duerr, M.A.; Hermanson, D.J.; Hedde, P.N.; Wong, J.S.; Vallim, T.Q.D.A.; Cravatt, B.F.; Gratton, E.; Ford, D.A.; et al. Intestinal Phospholipid Remodeling Is Required for Dietary-Lipid Uptake and Survival on a High-Fat Diet. Cell Metab. 2016, 23, 492-504. [CrossRef]

26. Keewan, E.; Narasimhulu, C.A.; Rohr, M.; Hamid, S.; Parthasarathy, S. Are Fried Foods Unhealthy? The Dietary Peroxidized Fatty Acid, 13-HPODE, Induces Intestinal Inflammation In Vitro and In Vivo. Antioxidants 2020, 9, 926. [CrossRef]

27. Whelan, J.; Fritsche, K. Linoleic Acid. Adv. Nutr. 2013, 4, 311-312. [CrossRef]

28. DiNicolantonio, J.J.; O'Keefe, J.H. Omega-6 vegetable oils as a driver of coronary heart disease: The oxidized linoleic acid hypothesis. Open Heart 2018, 5, e000898. [CrossRef]

29. Salerno, J.W.; Smith, D.E. The use of sesame oil and other vegetable oils in the inhibition of human colon cancer growth in vitro. Anticancer Res. 1991, 11, 209-215.

30. Rong, R.; Ramachandran, S.; Penumetcha, M.; Khan, N.; Parthasarathy, S. Dietary oxidized fatty acids may enhance intestinal apolipoprotein A-I production. J. Lipid Res. 2002, 43, 557-564. [CrossRef]

31. Auerbach, B.J.; Kiely, J.S.; Cornicelli, J.A. A spectrophotometric microtiter-based assay for the detection of hydroperoxy derivatives of linoleic acid. Anal. Biochem. 1992, 201, 375-380. [CrossRef] 
32. Andrews, S. FastQC -A Quality Control Tool for High Throughput Sequence Data. 2010. Available online: http://www. bioinformatics.babraham.ac.uk/projects/fastqc/ (accessed on 23 January 2020).

33. Bolger, A.M.; Lohse, M.; Usadel, B. Trimmomatic: A flexible trimmer for Illumina sequence data. Bioinformatics 2014, 30, 2114-2120. [CrossRef] [PubMed]

34. Kim, D.; Langmead, B.; Salzberg, S.L. HISAT: A fast spliced aligner with low memory requirements. Nat. Methods. 2015, 12, 357-360. [CrossRef] [PubMed]

35. Liao, Y.; Smyth, G.K.; Shi, W. featureCounts: An efficient general purpose program for assigning sequence reads to genomic features. Bioinformatics 2014, 30, 923-930. [CrossRef]

36. Love, M.I.; Huber, W.; Anders, S. Moderated estimation of fold change and dispersion for RNA-seq data with DESeq2. Genome Biol. 2014, 15, 550. [CrossRef]

37. Yu, G.; Wang, L.-G.; Han, Y.; He, Q.-Y. clusterProfiler: An R Package for Comparing Biological Themes Among Gene Clusters. Omics J. Integr. Biol. 2012, 16, 284-287. [CrossRef]

38. Luo, W.; Friedman, M.S.; Shedden, K.; Hankenson, K.D.; Woolf, P.J. GAGE: Generally applicable gene set enrichment for pathway analysis. BMC Bioinform. 2009, 10, 161. [CrossRef]

39. Wahli, W.; Michalik, L. PPARs at the crossroads of lipid signaling and inflammation. Trends Endocrinol. Metab. 2012, 23, 351-363. [CrossRef]

40. Pazienza, V.; Vinciguerra, M.; Mazzoccoli, G. PPARs Signaling and Cancer in the Gastrointestinal System. PPAR Res. 2012, 2012, 1-10. [CrossRef]

41. Zińczuk, J.; Maciejczyk, M.; Zaręba, K.; Romaniuk, W.; Markowski, A.; Kędra, B.; Zalewska, A.; Pryczynicz, A.; MatowickaKarna, J.; Guzińska-Ustymowicz, K. Antioxidant Barrier, Redox Status, and Oxidative Damage to Biomolecules in Patients with Colorectal Cancer. Can Malondialdehyde and Catalase Be Markers of Colorectal Cancer Advancement? Biomolecules $2019,9,637$.

42. Espinola-Klein, C.; Rupprecht, H.J.; Bickel, C.; Schnabel, R.; Genth-Zotz, S.; Torzewski, M.; Lackner, K.; Münzel, T.; Blankenberg, S. Glutathione Peroxidase-1 Activity, Atherosclerotic Burden, and Cardiovascular Prognosis. Am. J. Cardiol. 2007, 99, 808-812. [CrossRef] [PubMed]

43. Kobayashi, H.; Matsuda, M.; Fukuhara, A.; Komuro, R.; Shimomura, I. Dysregulated glutathione metabolism links to impaired insulin action in adipocytes. Am. J. Physiol. Metab. 2009, 296, E1326-E1334. [CrossRef]

44. Wojtal, K.A.; Eloranta, J.J; Hruz, P.; Gutmann, H.; Drewe, J.; Staumann, A.; Beglinger, C.; Fried, M.; Kullak-Ublick, G.A.; Vavricka, S.R. Changes in mRNA Expression Levels of Solute Carrier Transporters in Inflammatory Bowel Disease Patients. Drug Metab. Dispos. 2009, 37, 1871-1877. [CrossRef] [PubMed]

45. Schumann, T.; König, J.; Henke, C.; Willmes, D.M.; Bornstein, S.R.; Jordan, J.; Fromm, M.F.; Birkenfeld, A.L. Solute Carrier Transporters as Potential Targets for the Treatment of Metabolic Disease. Michel MC, editor. Pharmacol. Rev. 2020, 72, 343-379. [CrossRef] [PubMed]

46. Stelzer, G.; Rosen, N.; Plaschkes, I.; Zimmerman, S.; Twik, M.; Fishilevich, S.; Stein, T.I.; Nudel, R.; Lieder, I.; Mazor, Y.; et al. The GeneCards Suite: From Gene Data Mining to Disease Genome Sequence Analyses. Curr. Protoc. Bioinform. 2016, 54, 1-30. [CrossRef] [PubMed]

47. Marnett, L.J. Oxy radicals, lipid peroxidation and DNA damage. Toxicology 2002, 181-182, 219-222. [CrossRef]

48. Eilertsen, K.J.; Kazmierski, S.T.; Keller, T.C.S. Cellular titin localization in stress fibers and interaction with myosin II filaments in vitro. J. Cell Biol. 1994, 126, 1201-1210. [CrossRef]

49. Suh, H.N.; Huong, H.T.; Song, C.H.; Lee, J.H.; Han, H.J. Linoleic acid stimulates gluconeogenesis via Ca ${ }^{2+} / \mathrm{PLC}$, $\mathrm{CLA}_{2}$, and PPAR pathways through GPR40 in primary cultured chicken hepatocytes. Am. J. Physiol. Physiol. 2008, 295, C1518-C1527. [CrossRef]

50. de Vogel-van den Bosch, H.M.; Bünger, M.; de Groot, P.J.; Bosch-Vermeulen, H.; Hooiveld, G.J.E.J.; Müller, M. PPARalphamediated effects of dietary lipids on intestinal barrier gene expression. BMC Genom. 2008, 9, 231. [CrossRef]

51. Bünger, M.; van den Bosch, H.M.; van der Meijde, J.; Kersten, S.; Hooiveld, G.J.E.J.; Müller, M. Genome-wide analysis of PPAR $\alpha$ activation in murine small intestine. Physiol. Genom. 2007, 30, 192-204. [CrossRef]

52. Westerweel, P.E.; Luyten, R.K.M.A.C.; Koomans, H.A.; Derksen, R.H.W.M.; Verhaar, M.C. Premature atherosclerotic cardiovascular disease in systemic lupus erythematosus. Arthritis Rheum. 2007, 56, 1384-1396. [CrossRef] [PubMed]

53. Reinaud, O.; Delaforge, M.; Boucher, J.L.; Rocchiccioli, F.; Mansuy, D. Oxidative metabolism of linoleic acid by human leukocytes. Biochem. Biophys. Res. Commun. 1989, 161, 883-891. [CrossRef]

54. Ramana, K.V.; Srivastava, S.; Singhal, S.S. Lipid Peroxidation Products in Human Health and Disease. Oxid. Med. Cell. Longev. 2013, 2013, 583438. [CrossRef]

55. Cima, I.; Corazza, N.; Dick, B.; Fuhrer, A.; Herren, S.; Jakob, S.; Ayuni, E.; Mueller, C.; Brunner, T. Intestinal Epithelial Cells Synthesize Glucocorticoids and Regulate T Cell Activation. J. Exp. Med. 2004, 200, 1635-1646. [CrossRef] [PubMed]

56. Sidler, D.; Renzulli, P.; Schnoz, C.; Berger, B.; Schneider-Jakob, S.; Flück, C.; Inderbitzin, D.; Corazza, N.; Candinas, D.; Brunner, T. Colon cancer cells produce immunoregulatory glucocorticoids. Oncogene. 2011, 30, 2411-2419. [CrossRef] [PubMed]

57. Boivin, M.A.; Ye, D.; Kennedy, J.C.; Al-Sadi, R.; Shepela, C.; Ma, T.Y. Mechanism of glucocorticoid regulation of the intestinal tight junction barrier. Am. J. Physiol. Liver Physiol. 2007, 292, G590-G598. [CrossRef]

58. Wilckens, T.; De Rijk, R. Glucocorticoids and immune function: Unknown dimensions and new frontiers. Immunol. Today 1997, 18, 418-424. [CrossRef] 
59. Bruder, E.; Raff, H.; Goodfriend, T. An Oxidized Derivative of Linoleic Acid Stimulates Dehydroepiandrosterone Production by Human Adrenal Cells. Horm. Metab. Res. 2006, 38, 803-806. [CrossRef]

60. Bruder, E.D.; Ball, D.L.; Goodfriend, T.L.; Raff, H. An oxidized metabolite of linoleic acid stimulates corticosterone production by rat adrenal cells. Am. J. Physiol. Integr. Comp. Physiol. 2003, 284, R1631-R1635. [CrossRef]

61. Singh, M.; Kapoor, A.; Bhatnagar, A. Oxidative and reductive metabolism of lipid-peroxidation derived carbonyls. Chem. Biol. Interact. 2015, 234, 261-273. [CrossRef]

62. Vangaveti, V.N.; Jansen, H.; Kennedy, R.L.; Malabu, U.H. Hydroxyoctadecadienoic acids: Oxidised derivatives of linoleic acid and their role in inflammation associated with metabolic syndrome and cancer. Eur. J. Pharmacol. 2016, 785, 70-76. [CrossRef]

63. Márquez-Ruiz, G.; García-Martínez, M.C.; Holgado, F. Changes and Effects of Dietary Oxidized Lipids in the Gastrointestinal Tract. Lipid Insights 2008, 2, LPI-S904. [CrossRef]

64. Chester, A. The apolipoprotein B mRNA editing complex performs a multifunctional cycle and suppresses nonsense-mediated decay. EMBO J. 2003, 22, 3971-3982. [CrossRef]

65. Wang, G.; Bonkovsky, H.L.; de Lemos, A.; Burczynski, F.J. Recent insights into the biological functions of liver fatty acid binding protein 1. J. Lipid Res. 2015, 56, 2238-2247. [CrossRef] [PubMed]

66. Wang, Q.; Zhou, Y.; Rychahou, P.G.; Fan, T.W.-M.; Lane, A.N.; Weiss, H.L.; Evers, B.M. Ketogenesis contributes to intestinal cell differentiation. Cell Death Differ. 2017, 24, 458-468. [CrossRef]

67. Nakagawa, Y.; Satoh, A.; Tezuka, H.; Han, S.-I.; Takei, K.; Iwasaki, H.; Yatoh, S.; Yahagi, N.; Suzuki, H.; Iwasaki, Y.; et al. CREB3L3 controls fatty acid oxidation and ketogenesis in synergy with PPAR $\alpha$. Sci. Rep. 2016, 6, 39182. [CrossRef] [PubMed]

68. McDonnell, A.M.; Dang, C.H. Basic review of the cytochrome p450 system. J. Adv. Pract. Oncol. 2013, 4, 263-268. [PubMed]

69. Chang, G.W.M.; Kam, P.C.A. The physiological and pharmacological roles of cytochrome P450 isoenzymes. Anaesthesia. 1999, 54, 42-50. [CrossRef] [PubMed]

70. Zeng, C.-M.; Chang, L.-L.; Ying, M.-D.; Cao, J.; He, Q.-J.; Zhu, H.; Yang, B. Aldo-Keto Reductase AKR1C1-AKR1C4: Functions, Regulation, and Intervention for Anti-cancer Therapy. Front. Pharmacol. 2017, 8, 119. [CrossRef] [PubMed]

71. Barski, O.A.; Tipparaju, S.M.; Bhatnagar, A. The aldo-keto reductase superfamily and its role in drug metabolism and detoxification. Drug Metab. Rev. 2008, 40, 553-624. [CrossRef]

72. Fajardo, A.M.; MacKenzie, D.A.; Olguin, S.L.; Scariano, J.K.; Rabinowitz, I.; Thompson, T.A. Antioxidants Abrogate AlphaTocopherylquinone-Mediated Down-Regulation of the Androgen Receptor in Androgen-Responsive Prostate Cancer Cells. Languino LR, editor. PLoS ONE 2016, 11, e0151525. [CrossRef] [PubMed]

73. Dolfi, S.C.; Yang, Z.; Lee, M.-J.; Guan, F.; Hong, J.; Yang, C.S. Inhibitory Effects of Different Forms of Tocopherols, Tocopherol Phosphates, and Tocopherol Quinones on Growth of Colon Cancer Cells. J. Agric. Food Chem. 2013, 61, 8533-8540. [CrossRef] [PubMed]

74. Blokhina, O. Antioxidants, Oxidative Damage and Oxygen Deprivation Stress: A Review. Ann. Bot. 2003, 91, 179-194. [CrossRef] [PubMed]

75. Nordberg, J.; Arnér, E.S.J. Reactive oxygen species, antioxidants, and the mammalian thioredoxin system. Free Radic. Biol. Med. 2001, 31, 1287-1312. [CrossRef]

76. Wu, D.; Koga, T.; Martin, K.R.; Meydani, M. Effect of vitamin E on human aortic endothelial cell production of chemokines and adhesion to monocytes. Atherosclerosis 1999, 147, 297-307. [CrossRef]

77. Morel, S.; Didierlaurent, A.; Bourguignon, P.; Delhaye, S.; Baras, B.; Jacob, V.; Planty, C.; Elouahabi, A.; Harvengt, P.; Carlsen, H. Adjuvant System AS03 containing $\alpha$-tocopherol modulates innate immune response and leads to improved adaptive immunity. Vaccine 2011, 29, 2461-2473. [CrossRef]

78. Shi, H.; Noguchi, N.; Niki, E. Comparative study on dynamics of antioxidative action of $\alpha$-tocopheryl hydroquinone, ubiquinol, and $\alpha$-tocopherol against lipid peroxidation. Free Radic. Biol. Med. 1999, 27, 334-346. [CrossRef]

79. Bindoli, A.; Valente, M.; Cavallini, L. Inhibition of lipid peroxidation by alpha-tocopherolquinone and alpha-tocopherolhydroquinone. Biochem. Int. 1985, 10, 753-761.

80. Calviello, G. gamma-Tocopheryl quinone induces apoptosis in cancer cells via caspase-9 activation and cytochrome c release. Carcinogenesis 2003, 24, 427-433. [CrossRef]

81. Kwon, S.Y.; Massey, K.; Watson, M.A.; Hussain, T.; Volpe, G.; Buckley, C.D.; Nicolaou, A.; Badenhorst, P. Oxidised metabolites of the omega-6 fatty acid linoleic acid activate dFOXO. Life Sci. Alliance 2020, 3, e201900356. [CrossRef]

82. Mariadason, J.M.; Arango, D.; Corner, G.A.; Arañes, M.J.; Hotchkiss, K.A.; Yang, W.; Augenlicht, L.H. A gene expression profile that defines colon cell maturation in vitro. Cancer Res. 2002, 62, 4791-4804. [PubMed]

83. Beauchemin, N.; Arabzadeh, A. Carcinoembryonic antigen-related cell adhesion molecules (CEACAMs) in cancer progression and metastasis. Cancer Metastasis Rev. 2013, 32, 643-671. [CrossRef] [PubMed]

84. Marnett, L.J. Lipid peroxidation-DNA damage by malondialdehyde. Mutat. Res. Mol. Mech. Mutagen. 1999, 424, 83-95. [CrossRef]

85. Ma, Y.; Semba, S.; Khan, R.I.; Bochimoto, H.; Watanabe, T.; Fujiya, M.; Kohgo, Y.; Liu, Y.; Taniguchi, T. Focal adhesion kinase regulates intestinal epithelial barrier function via redistribution of tight junction. Biochim. Biophys. Acta-Mol. Basis Dis. 2013, 1832, 151-159. [CrossRef] [PubMed]

86. Beaulieu, J.F.; Quaroni, A. Clonal analysis of sucrase-isomaltase expression in the human colon adenocarcinoma Caco-2 cells. Biochem. J. 1991, 280, 599-608. [CrossRef] [PubMed] 
87. Thomas, S.; Prabhu, R.; Balasubramanian, K.A. Retinoid metabolism in the rat small intestine. Br. J. Nutr. 2005, 93, 59-63. [CrossRef] [PubMed]

88. Schuster, S.; Johnson, C.D.; Hennebelle, M.; Holtmann, T.; Taha, A.Y.; Kirpich, I.A.; Eguchi, A.; Ramsden, C.E.; Papouchado, B.G.; McClain, C.J.; et al. Oxidized linoleic acid metabolites induce liver mitochondrial dysfunction, apoptosis, and NLRP3 activation in mice. J. Lipid Res. 2018, 59, 1597-1609. [CrossRef] [PubMed]

89. Sullivan, E.M.; Pennington, E.R.; Green, W.D.; Beck, M.A.; Brown, D.A.; Shaikh, S.R. Mechanisms by Which Dietary Fatty Acids Regulate Mitochondrial Structure-Function in Health and Disease. Adv. Nutr. 2018, 9, 247-262. [CrossRef]

90. Lee, J.Y.; Hwang, D.H. The modulation of inflammatory gene expression by lipids: Mediation through Toll-like receptors. Mol. Cells 2006, 21, 174-185.

91. Lee, J.Y.; Plakidas, A.; Lee, W.H.; Heikkinen, A.; Chanmugam, P.; Bray, G.; Hwang, D.H. Differential modulation of Toll-like receptors by fatty acids. J. Lipid Res. 2003, 44, 479-486. [CrossRef]

92. Kamitani, H.; Geller, M.; Eling, T. Expression of 15-Lipoxygenase by Human Colorectal Carcinoma Caco-2 Cells during Apoptosis and Cell Differentiation. J. Biol. Chem. 1998, 273, 21569-21577. [CrossRef] [PubMed]

93. Brodkorb, A.; Egger, L.; Alminger, M.; Alvito, P.; Assunção, R.; Ballance, S.; Bohn, T.; Bourlieu-Lacanal, C.; Boutrou, R.; Carrière, F.; et al. INFOGEST static in vitro simulation of gastrointestinal food digestion. Nat. Protoc. 2019, 14, 991-1014. [CrossRef] [PubMed] 